\title{
Whole-genome sequencing of Puccinia striiformis f. sp. tritici mutant isolates identifies avirulence gene candidates
}

\author{
Yuxiang $\mathrm{Li}^{1}$, Chongjing Xia ${ }^{1}$, Meinan Wang ${ }^{1}$, Chuntao Yin ${ }^{1}$ and Xianming Chen ${ }^{1,2^{*}}$ (D)
}

\begin{abstract}
Background: The stripe rust pathogen, Puccinia striiformis f. sp. tritici (Pst), threats world wheat production. Resistance to Pst is often overcome by pathogen virulence changes, but the mechanisms of variation are not clearly understood. To determine the role of mutation in Pst virulence changes, in previous studies 30 mutant isolates were developed from a least virulent isolate using ethyl methanesulfonate (EMS) mutagenesis and phenotyped for virulence changes. The progenitor isolate was sequenced, assembled and annotated for establishing a high-quality reference genome. In the present study, the 30 mutant isolates were sequenced and compared to the wide-type isolate to determine the genomic variation and identify candidates for avirulence (Avr) genes.
\end{abstract}

Results: The sequence reads of the 30 mutant isolates were mapped to the wild-type reference genome to identify genomic changes. After selecting EMS preferred mutations, 264,630 and 118,913 single nucleotide polymorphism (SNP) sites and 89,078 and 72,513 Indels (Insertion/deletion) were detected among the 30 mutant isolates compared to the primary scaffolds and haplotigs of the wild-type isolate, respectively. Deleterious variants including SNPs and Indels occurred in 1866 genes. Genome wide association analysis identified 754 genes associated with avirulence phenotypes. A total of 62 genes were found significantly associated to 16 avirulence genes after selection through six criteria for putative effectors and degree of association, including 48 genes encoding secreted proteins (SPs) and 14 non-SP genes but with high levels of association $(P \leq 0.001)$ to avirulence phenotypes. Eight of the SP genes were identified as avirulence-associated effectors with high-confidence as they met five or six criteria used to determine effectors.

Conclusions: Genome sequence comparison of the mutant isolates with the progenitor isolate unraveled a large number of mutation sites along the genome and identified high-confidence effector genes as candidates for avirulence genes in Pst. Since the avirulence gene candidates were identified from associated SNPs and Indels caused by artificial mutagenesis, these avirulence gene candidates are valuable resources for elucidating the mechanisms of the pathogen pathogenicity, and will be studied to determine their functions in the interactions between the wheat host and the Pst pathogen.

Keywords: Stripe rust, Puccinia striiformis, Avirulence, Effector, Genomics, Mutation, Wheat, Yellow rust

\footnotetext{
* Correspondence: xianming@wsu.edu

Mention of trade names or commercial products in this publication is solely

for the purpose of providing specific information and does not imply

recommendation or endorsement by the U. S. Department of Agriculture.

USDA is an equal opportunity provider and employer.

'Department of Plant Pathology, Washington State University, Pullman, WA

99164-6430, USA

${ }^{2}$ USDA-ARS, Wheat Health, Genetics, and Quality Research Unit, Pullman, WA

99164-6430, USA
}

C C The Author(s). 2020 Open Access This article is licensed under a Creative Commons Attribution 4.0 International License, which permits use, sharing, adaptation, distribution and reproduction in any medium or format, as long as you give appropriate credit to the original author(s) and the source, provide a link to the Creative Commons licence, and indicate if changes were made. The images or other third party material in this article are included in the article's Creative Commons licence, unless indicated otherwise in a credit line to the material. If material is not included in the article's Creative Commons licence and your intended use is not permitted by statutory regulation or exceeds the permitted use, you will need to obtain permission directly from the copyright holder. To view a copy of this licence, visit http://creativecommons.org/licenses/by/4.0/. The Creative Commons Public Domain Dedication waiver (http://creativecommons.org/publicdomain/zero/1.0/) applies to the data made available in this article, unless otherwise stated in a credit line to the data. 


\section{Background}

Puccinia striiformis f. sp. tritici (Pst), the causal agent of wheat stripe (yellow) rust, is a threat to wheat production worldwide [1]. Wheat stripe rust can cause 100\% yield loss on susceptible cultivars in a single field when weather conditions are favorable for infection, but generally can cause up to $10 \%$ yield losses in large-scale regions or countries [1]. In the global scale, billions of dollars are spent annually on fungicide application for reducing stripe rust damage. Growing resistant cultivars is an effective and environmentally friendly way to control stripe rust. However, resistant cultivars may become susceptible few years after releasing due to virulence changes in the pathogen population [2,3]. For example, the breakdown of $Y r 17$ by Pst virulence races led to the epidemics of stripe rust in northern Europe from 1993 to 1999 [4]. In the recent decades, the Pst virulence spectrum has become wider and the Pst population is getting more aggressive in Europe, North America and other continents [2, 3, 5-7]. Taking the US as an example, the total identified races and emerging races are much higher in 2000-2009 than in 1968-1999 [6]. Accordingly, gaining a better understanding of mechanisms of Pst variation is crucial for monitoring Pst populations and developing strategies for more efficient control of stripe rust.

Mutation and somatic and sexual recombination have been demonstrated as principal mechanisms causing Pst variation [8-10]. Mutation is proposed to be the most important approach in creating new Pst races and genotypes [10]. Considering efficiency and power to produce mutations, ethyl methanesulfonate (EMS) is the most popular mutagen used by researchers in studying mutants of various organisms. EMS is an alkylating agent, which is known as inducing base substitutions in the genome strands. Of the single nucleotide polymorphisms (SNPs) caused by EMS, C/G to T/A transitions were most frequent in various organisms, including Arabidopsis thaliana [11, 12], Caenorhabditis elegans [13, 14], Lotus japonicus [15], Oryza sativa [12, 16] and Saccharomyces cerevisiae [17]. In addition to point mutations, EMS is able to generate insertions and deletions in genome sequences, which may result in phenotypic changes as well $[11,13,18,19]$. In rust fungi, Li et al. [10] developed a Pst mutant population through EMS mutagenesis and characterized the population with virulence and molecular markers. Salcedo et al. [20] obtained EMSinduced urediniospore mutants from the wheat stem rust pathogen Puccinia graminis f. sp. tritici (Pgt) Ug99, which led to the cloning of avirulence $(A v r)$ gene AvrSr35. Mutagenesis integrated with genomic sequencing is an efficient way to study the relationships between phenotypic traits and associated genes, leading to the identification of fungal effectors or avirulence genes.
The similar strategy has also been applied in cloning resistance genes in plant hosts [21].

Identifying and cloning avirulence genes are based on the gene-for-gene hypothesis proposed by Flor [22], which states that host $R$ genes confer resistance to the cognate Avr genes in the pathogen. During the infection of pathogens, the first layer of host defense is pathogen-associated molecular pattern (PAMP)-triggered immunity (PTI). When PTI is crashed by pathogen effectors, stronger defense responses, referred as effector-triggered immunity (ETI), are triggered, leading to hypersensitive responses [23]. The increasing variation of pathogen virulence is due to the arm race between pathogen Avr effectors and corresponding host resistance $(\mathrm{R})$ proteins, causing the rapid evolution of the pathogen [24]. To date, a handful of $A v r$ genes have been molecularly identified in rust pathogens, including AvrL567, AvrP123, AvrP4, AvrM, AvrL2 and AvrM14 from the flax rust pathogen Melampsora lini (M. lini) together with PGTAUSPE10-1, AvrSr35 and AvrSr50 from Pgt [18, 25-28]. In Pst, Dagvadorj et al. [29] reported that PstSCR1 can activate immunity in non-host plants. Zhao et al. [30] found that Pst_8713 was involved in enhancing Pst virulence and suppressing plant immunity. Yang et al. [31] identified that Pst18363 displayed an important pathogenicity factor in Pst. However, no known Avr genes have been identified in Pst so far.

With the rapid development of sequencing technologies, the genome sequences of Pst are available, which makes it possible to further understand the pathogenesis of the obligate biotrophic fungal parasite [32-38]. The advancement of genome sequencing has led everexpanding candidate effector genes identified in Pst. Cantu et al. [33] identified five Pst candidate effector genes from 2999 predicted secreted protein (SP) genes. Xia et al. [39] predicted a set of 25 Pst Avr candidate genes from 2146 predicted SPs by combining comparative genomics with association analyses. Similar approaches were also used in detecting $A v r$ candidate genes in Puccinia triticina (Pt), the wheat leaf rust pathogen [40]. These predicted effectors are determined based on the characteristics from previous identified effectors. In rust pathogens, even with some exceptions, most effectors have shared some common features, such as secreted, small size, cysteine-rich, species-specific, polymorphic, no conserved protein domains and haustorially expressed [33, 41-43]. Unlike a conserved motif RxLR noted in oomycetes effectors [44], no common sequence motifs of fungi effectors were detected through bioinformatic analyses [45]. One of the sporadic exceptions is in the barley powdery mildew pathogen, Blumeria graminis f. sp. hordei $(B g h)$ with some effectors sharing a conserved N-terminal $[\mathrm{Y} / \mathrm{F} / \mathrm{W}] \mathrm{xC}$ motif [46]. This motif has also been reported in rust fungi, Melampsora larici-populina and Pgt, but not limited to the $\mathrm{N}$ - 
terminal region [47]. Even though there is no a one-sizefits-all standard to identify candidate effectors, those features are still useful in detecting effectors in an expanding number of fungal species.

To determine and characterize the potential Avr effectors in Pst, in the present study we generated and analyzed whole-genome sequences of EMS-induced mutants. By comparing with the progenitor isolate genome, SNPs and Indels (Insertion/deletion) were found from the mutant isolates. By filtering out the low-quality and low-impact variants, genome association analyses identified 754 genes significantly associated with Pst avirulence/virulence phenotypes. We further predicted 48 genes as SP genes and 8 of them as putative effector genes with high confidence. Additionally, fourteen nonSP genes that were highly associated $(P \leq 0.001)$ to individual avirulence genes were also worthy being studied for their effects on avirulence. This study was the first in Pst that integrated mutagenesis, genomics analysis and association analysis for mining effectors. The identified avirulence candidates should be further studied to determine their functions in the plant-pathogen interactions, providing useful information for developing new approaches for monitoring the pathogen population and more effective strategies for controlling the disease.

\section{Results}

Virulence characterization of the progenitor and mutant isolates

The Pst isolate 11-281 was chosen as the progenitor isolate because it is avirulent on all $18 Y r$ single-gene lines used to differentiate Pst races. Thirty mutant isolates were selected for the present study from 33 EMSinduced mutant isolates based on their avirulence/virulence patterns characterized on the 18 wheat $\mathrm{Yr}$ singlegene differentials in the previous study [10]. Compared with the infection types (IT 1 or 2 ) of the wild-type isolate on the 18 wheat differentials, changes from avirulence to virulence occurred on all $\mathrm{Yr}$ single-gene lines to different extents except for $Y r 5$ and $Y r 15$. Thus, phenotypic changes of avirulence to virulence could be studied for avirulence genes corresponding to $16 \mathrm{Yr}$ resistance genes (Yr1, Yr6, Yr7, Yr8, Yr9, Yr10, Yr17, Yr24, Yr27, Yr32, Yr43, Yr44, YrSP, YrTr1, YrExp2 and Yr76) using the 30 selected mutant isolates. The IT data of the wildtype isolate and 30 mutant isolates and the frequency of virulent mutant isolates are provided in Additional file 1: Table S1, and the IT patterns of the 30 mutant isolates on the $18 \mathrm{Yr}$ single-gene lines, as well as a dendrogram showing their relationships based on the IT data, are illustrated in Fig. 1. The frequencies of the changed virulence factors corresponding to the $16 \mathrm{Yr}$ genes among the 30 mutant isolates ranged from 21.2\% (Yr32) to $78.8 \%(Y r 9)$. The relative balances of avirulent to virulent phenotypes among the 30 mutant isolates indicate that these isolates are suitable for studying markers related to the 16 avirulence/virulence loci using associate analysis.

\section{Genome alignment and sequence variation}

The high-quality genome (accession SBIN00000000) of the progenitor isolate (11-281), obtained through PacBio, Illumina and RNA sequencing as previously reported [49], was used as the reference genome in the present study. The assembled sequence comprised 381 primary scaffolds and 873 haplotigs with the genome size of $84.75 \mathrm{Mb}$ and 60.09 $\mathrm{Mb}, 16,869$ and 12,145 protein-coding genes and 1829 and 1318 SP genes, respectively. The mutant isolates were sequenced by Illumina sequencing with an estimated average coverage of 30x. The 30 raw reads are publicly available in the National Center of Biological Information (NCBI) with SRA accession SRR10413520 to SRR10413549. After aligning the 30 mutant sequences to the reference genome and treating the alignment by a series of analytical software, BAM files were obtained. The mapping rates of alignments ranged from 65.36 to $71.93 \%$ by comparing with the primary scaffolds and 56.36 to $62.50 \%$ with the haplotigs of the wild-type isolate genome (Additional file 1: Table S2).

By mapping the Illumina reads of the wild-type isolates (11-281) to the reference genomes, we identified 196, 350 SNPs and 173,075 Indels from its primary scaffolds and 48,647 SNPs and 7612 Indels from its haplotigs. The heterozygous sites were then removed from the variants we obtained. After separating variants from the alignments and keeping only the EMS-induced SNPs, the number of SNPs ranged from 9353 to 117,035 among the 30 mutants detected from the primary scaffolds. The heterozygous rates extended from 70.92 to $99.07 \%$ (Table 1). The densities and distribution of SNPs on the primary scaffolds were displayed in Fig. 2 and Additional file 1: Table S3. A phylogenetic tree was constructed to show the genetic relationships among the mutant isolates using the SNPs (Additional file 2: Fig. S1), indicating that EMS mutagenesis is able to create various degrees of genomic variation. The number of Indels ranged from 4005 to 20,705 in the 30 mutant isolates. The most frequent Indel length was $1 \mathrm{bp}$ (46.90\%), followed by 2 bp (18.69\%) and $3 \mathrm{bp}(8.65 \%)$, counting for $74.24 \%$ Indels. To the extreme, a 273-bp insertion and a 245-bp deletion were the largest Indels detected in this study (Additional file 1: Table S4). Likewise, the Indel distribution and density varied among scaffolds (Fig. 2; Additional file 1: Table S3). SNPs and Indels were also identified from the haplotigs, and the results were displayed in Additional file 1: Table S5.

Prediction of the effects of the variants on the genome was implemented using SnpEff. It should be noted that one variant might cause multiple effects in the genome, the 264,630 and 118,913 SNPs derived from the primary 


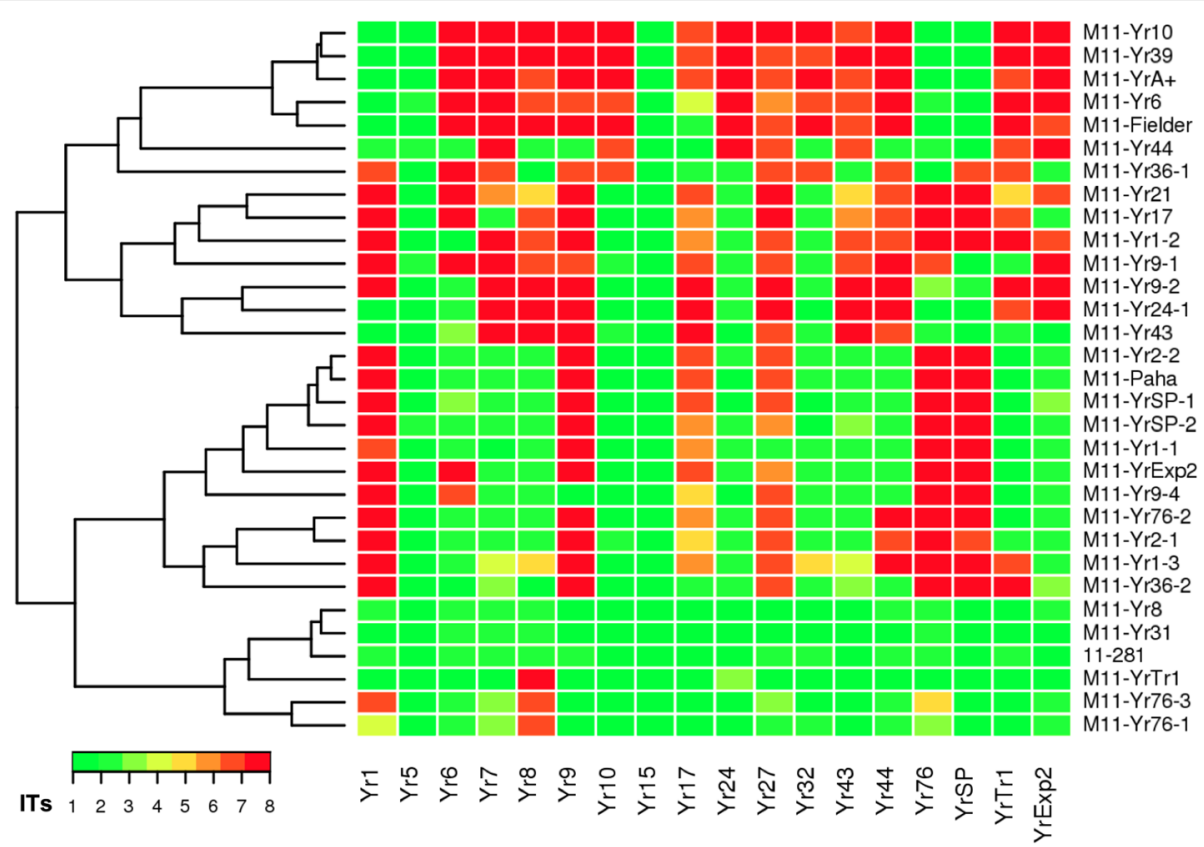

Fig. 1 Heatmap and dendrogram of wild-type isolate 11-281 and its mutants of Puccinia striiformis f. sp. tritici based on infection types (ITs). The virulence characterization of all isolates was conducted on the 18 wheat Yr single-gene differentials [48]. ITs 1 to 8 were transformed to the color key ranging from green to red, which indicate avirulent (resistant) to virulent (susceptible) reactions

scaffolds and haplotigs accounted for 782,566 and 369, 000 effects, respectively. The 89,078 and 72,513 Indels caused 307,134 and 250,464 effects, respectively. The effect types of SNPs and frequency of each category were displayed in Fig. 3a. The effects of SNPs were mainly in downstream (33.50\%), upstream (32.17\%) and intergenic (22.43\%) regions, followed by synonymous $(4.08 \%)$, intron $(3.62 \%)$ and missense (3.47\%) variants. Since missense, splice, start loss and stop gain variants were predicted to have a moderate or high impact on the genome, those variants were regarded as deleterious mutations resulting in the impact on gene functions (http:// snpeff.sourceforge.net/SnpEff_manual.html). Missense variants were the predominant (84.65\%) among all the deleterious mutations (Fig. 3b). Similarly, the effects of Indels were mostly in downstream (34.48\%), upstream (34.00\%) and intergenic (22.63\%) regions (Fig. 4a) The percentage of moderate to high-impact effect were illustrated in Fig. 4b, of which frameshift variants were the most frequent $(60.84 \%)$ among all deleterious Indels. The types and frequencies of SNP and Indel effects detected from the haplotigs are displayed in Additional file 2: Fig. S2 and Fig. S3.

\section{Pst effector genes as candidates for Avr genes}

Deleterious SNPs and Indels were selected from the associated variants according to their impact on the genome. Deleterious variants detected from the primary scaffolds and haplotigs were analysed and summarized in Table 2 and Table 3, respectively. As shown in Table 2, deleterious SNPs extended from 133 (M11-Yr8 and M11-Yr31) to 1821 (M11-Yr36-1) with the involving genes ranging from 66 (M11-Yr8) to 682 (M11-Yr36-1). Of the deleterious Indels, the number ranged from 40 (M11-Yr8) to 271 (M11-YrTr1) involving in 28 (M11Yr8) to 125 (M11-YrTr1) genes. These SNPs and Indels were found to be involved in 1135 genes (Table 2). Similarly, deleterious variants identified from the haplotigs varied among different mutant isolates with 731 involving genes (Table 3). Overall, 1866 genes were inferred from the variants detected from both the primary scaffolds and haplotigs.

To identify inferred genes associated to avirulence, genome-wide association analysis was conducted using the avirulence/virulence phenotype data and genes with deleterious mutants. Genes with probability $(P)$ values $\leq 0.05$ in the association analysis were regarded as significantly associated with the avirulence/virulence phenotypes. Predicted effector candidates were obtained from the associated proteins based on the criteria of with $\mathrm{N}$ terminal signal peptide and without transmembrane helix. A total of 754 genes were found significantly associated with $16 \mathrm{Avr}$ loci, of which $48 \mathrm{SP}$ genes were predicted to be effector candidate genes (Table 4, Table 5). Associated SP genes were identified for all 16 Avr loci that had varied phenotypes among the 30 mutant isolates. $A v Y r 27$ had the highest number of associated genes (149). AvYr27 also had the most associated SP 
Table 1 Numbers and percentages of heterozygous and homozygous of EMS-induced SNPs in mutant isolates of Puccinia striiformis $\mathrm{f}$. sp. tritici detected by mapping to the primary scaffolds of isolate 11-281

\begin{tabular}{|c|c|c|c|c|c|}
\hline \multirow{2}{*}{$\begin{array}{l}\text { Mutant } \\
\text { isolates }\end{array}$} & \multirow{2}{*}{$\begin{array}{l}\text { No. of } \\
\text { SNPS }\end{array}$} & \multicolumn{2}{|c|}{ Heterozygous } & \multicolumn{2}{|c|}{ Homozygous } \\
\hline & & No. & Percent $(\%)^{a}$ & No. & Percent $(\%)^{b}$ \\
\hline M11-Yr36-1 & 117,035 & 109,070 & 91.84 & 3726 & 8.16 \\
\hline M11-Yr21 & 115,281 & 103,417 & 71.05 & 17,707 & 28.95 \\
\hline M11-YrTr1 & 113,504 & 99,896 & 97.78 & 208 & 2.22 \\
\hline M11-Yr24-1 & 112,757 & 98,611 & 93.91 & 5463 & 6.09 \\
\hline M11-Yr9-2 & 109,247 & 100,435 & 97.94 & 201 & 2.06 \\
\hline M11-Yr17 & 100,118 & 92,493 & 99.07 & 227 & 0.93 \\
\hline M11-Yr39 & 89,676 & 84,213 & 71.65 & 17,350 & 28.35 \\
\hline M11-Yr10 & 86,237 & 80,478 & 93.54 & 5508 & 6.46 \\
\hline M11-YrA+ & 86,114 & 80,365 & 97.74 & 223 & 2.26 \\
\hline M11-Yr9-1 & 85,723 & 80,208 & 93.57 & 5515 & 6.43 \\
\hline M11-Fielder & 85,258 & 79,750 & 87.45 & 14,146 & 12.55 \\
\hline M11-Yr6 & 85,195 & 79,658 & 88.01 & 13,608 & 11.99 \\
\hline M11-Yr9-4 & 72,356 & 61,995 & 71.52 & 17,402 & 28.48 \\
\hline M11-Yr1-2 & 71,929 & 60,913 & 92.49 & 3470 & 7.51 \\
\hline M11-Yr1-3 & 62,064 & 53,728 & 93.32 & 5749 & 6.68 \\
\hline M11-YrSP-1 & 61,507 & 44,014 & 91.93 & 8812 & 8.07 \\
\hline M11-Yr2-1 & 61,352 & 43,571 & 98.12 & 191 & 1.88 \\
\hline M11-Yr76-2 & 61,243 & 43,742 & 71.02 & 17,781 & 28.98 \\
\hline M11-YrExp2 & 61,198 & 43,848 & 70.92 & 17,722 & 29.08 \\
\hline M11-Yr2-2 & 61,171 & 43,464 & 85.68 & 10,361 & 14.32 \\
\hline M11-Paha & 61,094 & 43,692 & 86.57 & 8336 & 13.43 \\
\hline M11-Yr36-2 & 60,944 & 43,222 & 93.32 & 5759 & 6.68 \\
\hline M11-YrSP-2 & 60,943 & 43,717 & 71.42 & 17,501 & 28.58 \\
\hline M11-Yr76-1 & 46,186 & 42,716 & 89.71 & 11,864 & 10.29 \\
\hline M11-Yr76-3 & 45,671 & 41,945 & 93.19 & 7965 & 6.81 \\
\hline M11-Yr43 & 24,453 & 24,226 & 92.38 & 7625 & 7.62 \\
\hline M11-Yr44 & 10,139 & 9948 & 71.56 & 17,493 & 28.44 \\
\hline M11-Yr1-1 & 9881 & 9658 & 71.73 & 17,226 & 28.27 \\
\hline M11-Yr8 & 9768 & 9567 & 84.68 & 11,016 & 15.32 \\
\hline M11-Yr31 & 9353 & 9145 & 93.50 & 5537 & 6.50 \\
\hline Average & 67,913 & 58,724 & 86.47 & 9190 & 13.53 \\
\hline
\end{tabular}

${ }^{a}$ The percentage of heterozygous SNPs was calculated as the number of heterozygous SNPs divided by the total number of SNPs of each isolate times 100

${ }^{\mathrm{b}}$ The percentage of heterozygous SNPs was calculated as the number of homozygous SNPs divided by the total number of SNPs of each isolate times 100

genes (10) together with $A v Y r 7$. $A v Y r 8$ had 27 associated genes including $1 \mathrm{SP}$ gene. Only one SP gene was found for each of $A v Y r 1, A v Y r 24$ and $A v Y r 76$ (Table 4).

To identify highly associated genes, 17 genes with $P$ values $\leq 0.001$ were identified from the 754 associated genes, of which 3 were SP and 14 were non-SP genes. The 17 genes were found highly associated to eight Avr loci, including $A v Y r 6, A \nu Y r 7, A v Y r 8, A v Y r 9, A v Y r 24$, $A v Y r 27, A v Y r 32$ and $A v Y r S P$. Four genes were associated to $A v Y r 8, A v Y r 27$ and $A v Y r S P$, two genes to $A v Y r 9$ and one gene to $A v Y r 6, A v Y r 7, A v Y r 24$ and $A v Y r 32$. As an example, four genes associated to $A v Y r 8$ and $A v Y r S P$ are shown in Fig. 5a and Fig. 5b. Except for one gene (PS_11281_haploid_00002745), which was associated to AvYr24 and $A v Y r 32$, each of the other 16 genes was associated to a single $A v r$ locus. Of these 17 highly associated genes, missense variants were the majority. Five genes had frameshifts, 3 had gained stop codons, 2 had Inframe insertions and only 1 lost the start codon (Additional file 1: Table S6). Fourteen out of the 17 highly associated genes were not SP genes (Table 6). Thus, a total of 62 genes, including 48 effector candidate genes and 14 non-SP genes, were considered as candidates for avirulence genes. Their genomic locations and derived amino acids are provided in Additional file 3: Table SE1.

\section{Characterization of Pst effector gene candidates}

A series of six criteria, including short amino acid sequence, cysteine rich, predicted by EffectorP, genus or species specific, no known domain, and polymorphic within species, were used to evaluate the 62 avirulence gene candidates to obtain effectors with high confidence (Fig. 6). Of the 62 candidates, 11 were predicted to encode small SPs with amino acid length less than 300. Fifteen putative effectors were identified as cysteine-rich proteins with the percentage of cysteine not less than $3 \%$. The avirulence gene candidates were further analyzed using EffectorP, a machine learning fungal effector predictor, and seven of them passed through the criterion and were predicted to be effectors with the possibility greater than $55 \%$. Domains of protein functions were determined by searching the Pfam protein families and InterPro database. No known PFAM domains were found for 37 candidates. Similar results were obtained through searching the InterPro database. Genus and species specific proteins were identified from the orthologous groups, and 34 of the candidates were identified to be Puccinia or P. striiformis specific proteins through genomic comparison of protein sequences from 13 fungal isolates belonging to 10 species. A phylogenetic tree was generated with these genes using a new rapid hillclimbing algorithm with the GTRGAMMA model. Isolates belonging to ascomycetes and basidiomycetes were assigned to two various clans (Additional file 2: Fig. S4). Isolates of $P$. striiformis were in a cluster closely related to $P$. triticina, $P$. graminis and $P$. coronate; and the wildtype isolate Pst 11-281 was tightly clustered with other three P. striiformis isolates (Pst 104E137A-, Pst 93-210 and Psh 93TX-2), which have high-quality genomes. Of the 34 genus or species specific genes, 22 were Puccinia 


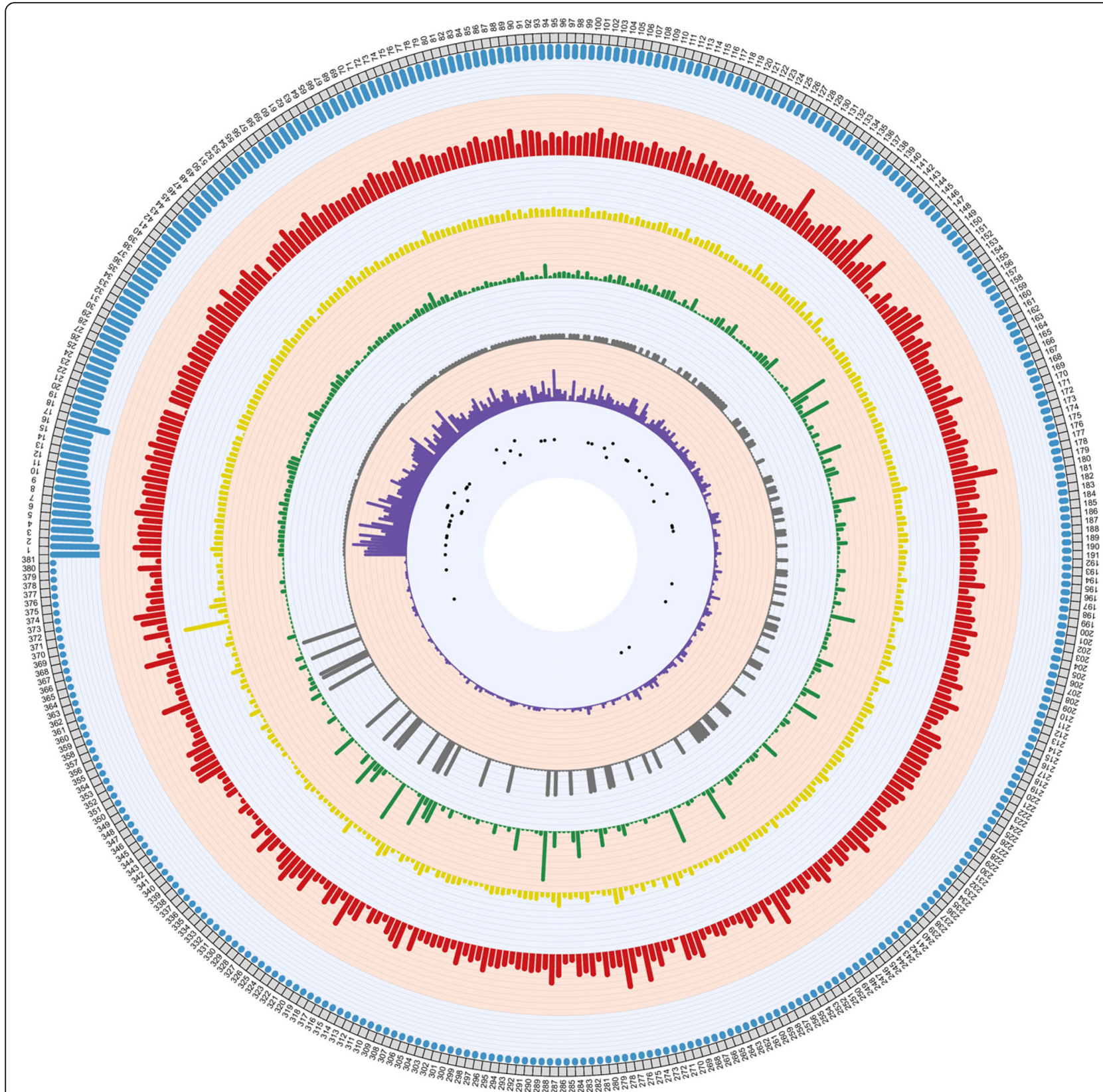

Fig. 2 Genome-wide identification of variants (SNPs and/or Indels), variants densities, distribution of secreted proteins (SPs) and effector candidates from primary assembled scaffolds. The grey bars in the outer layer are the scaffolds of the reference genome, and each axis indicates the genome size of $150 \mathrm{~Kb}$. The first layer in red and second layer in yellow indicate SNP and Indel densities throughout the genome, respectively. Each axis represents 1000 SNPs or Indels per Mb. The third layer in green and the fourth layer in grey exhibits densities if deleterious SNPs and Indel in the scaffolds. Each axis shows 70 SNPs or Indels per Mb. The fifth layer in purple displayed the distribution of SPs in the genome, and each axis indicates 4 SPs. The black dots in the inner layer represent the effector candidates distributed in the scaffolds

specific and 12 P. striiformis specific; and four of them were basidiomycete orthologs (Additional file 3: Table SE2). The polymorphisms of candidate effectors were identified by searching the existing $P$. striiformis protein database using Blastp. No effector candidates were found to be a $P$. striiformis specific and all the 62 candidate genes were found to be polymorphic to at least one isolate among the four P. striiformis isolates with highquality proteomes (Additional file 3: Table SE3). The numbers of criteria of the 62 candidate genes, which were separated into two groups of either SP genes or non-SP genes but with high association $(P<0.001)$, are shown in Fig. 7a and b, respectively; and summarized in Fig. 7c. Of the 48 SP genes, 6 genes met all six criteria 


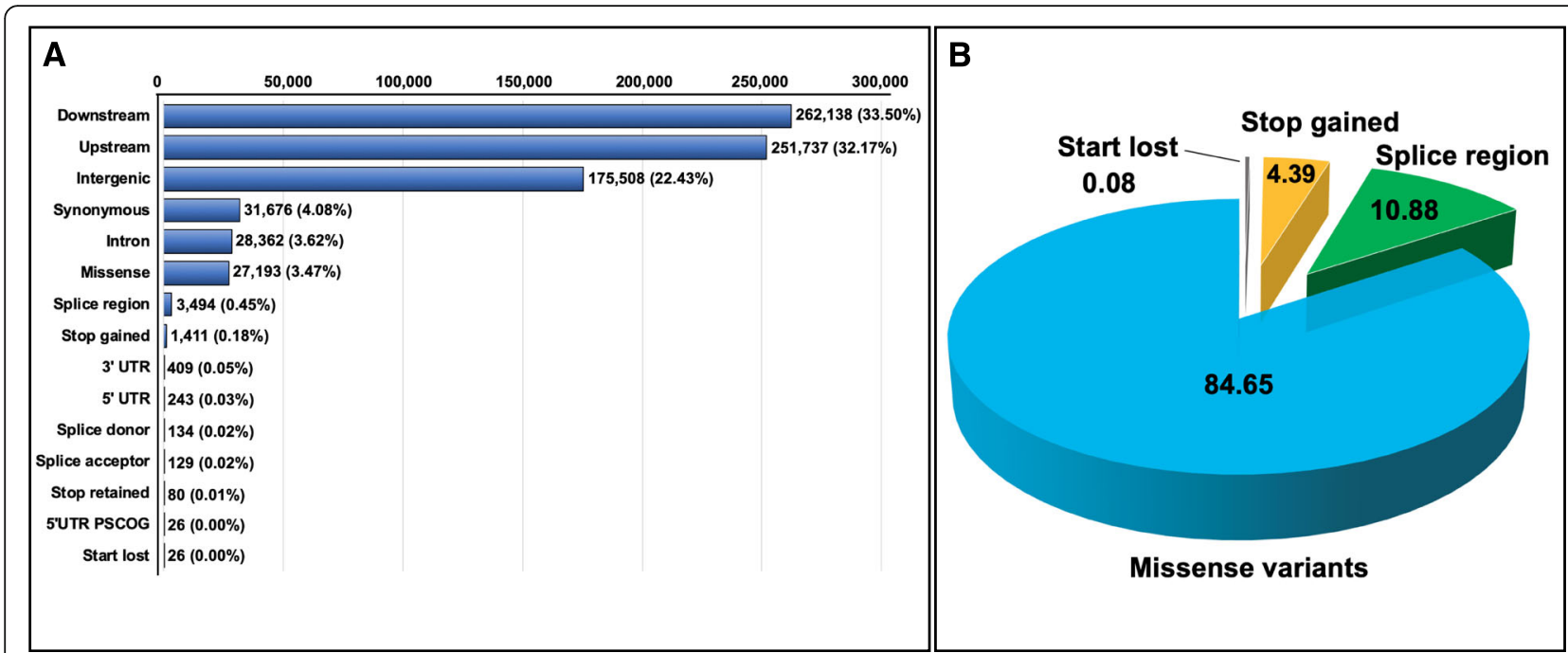

Fig. 3 Types and frequencies of SNP effects detected from the primary scaffolds. a: The number and percentage of all EMS-induced SNPs for each type of effects. 5' UTR PSCOG is the acronym of 5' UTR premature start codon gain variant. Stop gained and start lost indicted the variants derived from gaining a stop codon and losing a start codon. $\mathbf{b}$ : The types and percentages of SNP effects, including missense, splice, stop gained and start lost variants, were identified as deleterious effects, and the number of each SNP effect indicates the percentage contributed to the total deleterious effects

and 2 met five criteria (Fig. 7a, Table 5, Additional file 2: Fig. S5A). Among the 14 non-SP genes with high association $(P$ value $\leq 0.001)$ to avirulence/virulence phenotypes, 3 met four and 1 met three criteria, and the rest 10 met one or two criteria (Fig. 7b, Table 6, Additional file 2: Fig. S5B). These candidates derived from high-degree associated non-SP are more likely to be the irregular or non-effector genes with distinctive characteristics compared with identified effectors.
When the two groups were put together, eight genes met at least five of the criteria and therefore, were considered as candidates for avirulence genes with high confidence. Six of them met all six criteria. Thus, the six genes, PS_11-281_00004726, PS_11-281_00016865, PS_ 11-281_00015631, PS_11-281_00002472, PS_11-281_ 00009923 and PS_11-281_haploid_00011016, were predicted to be Pst effectors with the highest confidence. Effector gene PS_11-281_00004726 was associated to

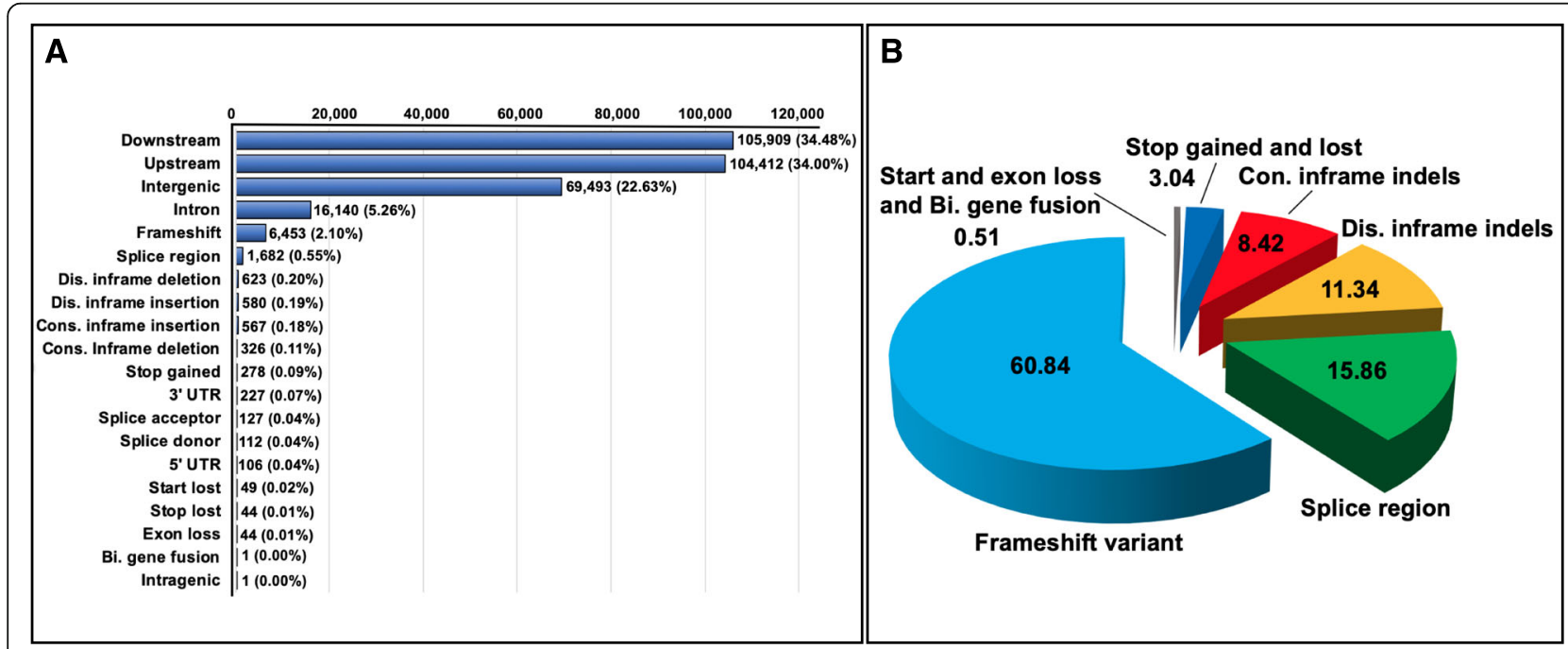

Fig. 4 Types and frequencies of Indels effects found from the primary scaffolds. a: The number and percentage of all EMS-induced Indels for each type of effects. Bi. is the abbreviation of bidirectional gene fusion, indicates fusion of two genes in opposite directions. Con. and Dis. are the abbreviation of conserved and disruptive. Splice acceptor and donor mean the variant hits a splice acceptor site. $\mathbf{b}$ : The types and percentages of deleterious Indels effects. The number shows the proportion in percentage of each variant effect out of the total deleterious effects 
Table 2 Numbers of deleterious SNPs, Indels and corresponded genes in mutant isolates of Puccinia striiformis f. sp. tritici detected from the primary scaffolds of isolate 11-281

\begin{tabular}{|c|c|c|c|c|c|}
\hline $\begin{array}{l}\text { Mutant } \\
\text { Isolate }\end{array}$ & $\begin{array}{l}\text { Deleterious } \\
\text { SNPs }^{a}\end{array}$ & $\begin{array}{l}\text { Deleterious SNPS } \\
\text { on genes }\end{array}$ & Deleterious Indels ${ }^{c}$ & $\begin{array}{l}\text { Deleterious indels } \\
\text { on genes }\end{array}$ & $\begin{array}{l}\text { Deleterious SNPs and } \\
\text { Indels on genes }\end{array}$ \\
\hline M11-Yr36-1 & 1821 & 682 & 217 & 121 & 716 \\
\hline M11-Yr21 & 1820 & 664 & 254 & 123 & 698 \\
\hline M11-YrTr1 & 1612 & 641 & 271 & 125 & 682 \\
\hline M11-Yr24-1 & 1722 & 650 & 201 & 106 & 678 \\
\hline M11-Yr9-2 & 1695 & 651 & 218 & 117 & 688 \\
\hline M11-Yr17 & 1528 & 609 & 164 & 92 & 640 \\
\hline M11-Yr39 & 1371 & 544 & 120 & 77 & 582 \\
\hline M11-Yr10 & 1280 & 492 & 120 & 85 & 522 \\
\hline M11-YrA+ & 1273 & 509 & 128 & 76 & 537 \\
\hline M11-Yr9-1 & 1295 & 501 & 144 & 74 & 529 \\
\hline M11-Fielder & 1317 & 503 & 176 & 91 & 532 \\
\hline M11-Yr6 & 1280 & 499 & 170 & 95 & 532 \\
\hline M11-Yr9-4 & 1134 & 491 & 152 & 98 & 543 \\
\hline M11-Yr1-2 & 1132 & 505 & 173 & 109 & 566 \\
\hline M11-Yr1-3 & 972 & 426 & 163 & 101 & 482 \\
\hline M11-YrSP-1 & 988 & 425 & 192 & 115 & 486 \\
\hline M11-Yr2-1 & 981 & 426 & 202 & 114 & 491 \\
\hline M11-Yr76-2 & 970 & 423 & 198 & 114 & 488 \\
\hline M11-YrExp2 & 965 & 424 & 190 & 120 & 492 \\
\hline M11-Yr2-2 & 971 & 421 & 187 & 111 & 484 \\
\hline M11-Paha & 943 & 416 & 189 & 113 & 480 \\
\hline M11-Yr36-2 & 952 & 419 & 216 & 121 & 490 \\
\hline M11-YrSP-2 & 960 & 421 & 171 & 105 & 483 \\
\hline M11-Yr76-1 & 844 & 323 & 112 & 69 & 357 \\
\hline M11-Yr76-3 & 838 & 318 & 109 & 64 & 349 \\
\hline M11-Yr43 & 391 & 217 & 93 & 56 & 247 \\
\hline M11-Yr44 & 142 & 81 & 78 & 36 & 100 \\
\hline M11-Yr1-1 & 151 & 77 & 58 & 31 & 99 \\
\hline M11-Yr8 & 133 & 66 & 40 & 28 & 83 \\
\hline M11-Yr31 & 133 & 72 & 54 & 32 & 88 \\
\hline Total $^{d}$ & 4217 & 1042 & 1122 & 412 & 1135 \\
\hline
\end{tabular}

${ }^{a}$ Associated deleterious SNPs were selected based on the types of variants annotated using the SnpEff program. SNPs with moderate and high effects were considered as deleterious SNPs

${ }^{b}$ Associated genes were deduced from the annotated file generated using the SnpEff program. Multiple SNPs can occur in one gene

${ }^{c}$ Associated deleterious indels were selected based on the types of variants annotated using the SnpEff program. Indels with moderate and high effects were considered as deleterious Indels

${ }^{\mathrm{d}}$ SNPs, Indels and genes can be shared in different mutant isolates, so the total number is not equal to summation of individuals

avirulence loci $A v Y r 1$, PS_11-281_00016865 was associated to AvYr6, PS_11-281_00015631 was associated to $A v Y r 7$, PS_11-281_00002472 was associated to $A v Y r 7$, PS_11-281_00009923 was associated to AvYr76 and PS_ 11-281_haploid_00011016 was associated to AvYr17 (Table 5). The SNP and Indel sites occurred in these six effector genes and the resulting amino acids changes are shown in Fig. 8. Although not fitting all six criteria, two genes (PS_11-281_00011501 and PS_11-281_00002262) were still considered as Pst effectors associated to avirulence with high confidence as they met five of the six standards. Despite meeting fewer than five effector standards, the rest of 54 candidates were still possible avirulence candidates, and worthy to be included in functional studies. 
Table 3 Numbers of deleterious SNPs, indels and corresponded genes in mutant isolates of Puccinia striiformis f. sp. tritici detected from the haplotigs of isolate 11-281

\begin{tabular}{|c|c|c|c|c|c|}
\hline $\begin{array}{l}\text { Mutant } \\
\text { Isolate }\end{array}$ & Deleterious SNPS & $\begin{array}{l}\text { Deleterious SNPs } \\
\text { on genes }\end{array}$ & Deleterious Indels & $\begin{array}{l}\text { Deleterious Indels } \\
\text { on genes }\end{array}$ & $\begin{array}{l}\text { Deleterious variants } \\
\text { on genes }\end{array}$ \\
\hline M11-Yr36-1 & 147 & 85 & 73 & 50 & 124 \\
\hline M11-Yr21 & 243 & 125 & 146 & 95 & 192 \\
\hline M11-YrTr1 & 211 & 127 & 158 & 92 & 190 \\
\hline M11-Yr24-1 & 476 & 215 & 349 & 175 & 326 \\
\hline M11-Yr9-2 & 226 & 119 & 123 & 69 & 170 \\
\hline M11-Yr17 & 578 & 278 & 250 & 140 & 360 \\
\hline M11-Yr39 & 348 & 174 & 227 & 117 & 252 \\
\hline M11-Yr10 & 248 & 135 & 165 & 96 & 202 \\
\hline M11-YrA+ & 347 & 166 & 217 & 112 & 242 \\
\hline M11-Yr9-1 & 218 & 116 & 133 & 78 & 177 \\
\hline M11-Fielder & 233 & 116 & 148 & 95 & 183 \\
\hline M11-Yr6 & 180 & 99 & 123 & 74 & 154 \\
\hline M11-Yr9-4 & 664 & 304 & 383 & 207 & 417 \\
\hline M11-Yr1-2 & 806 & 338 & 557 & 252 & 476 \\
\hline M11-Yr1-3 & 334 & 184 & 161 & 111 & 259 \\
\hline M11-YrSP-1 & 393 & 213 & 261 & 156 & 309 \\
\hline M11-Yr2-1 & 777 & 354 & 545 & 264 & 491 \\
\hline M11-Yr76-2 & 461 & 235 & 316 & 185 & 352 \\
\hline M11-YrExp2 & 392 & 218 & 269 & 157 & 317 \\
\hline M11-Yr2-2 & 844 & 363 & 631 & 280 & 522 \\
\hline M11-Paha & 714 & 329 & 500 & 244 & 462 \\
\hline M11-Yr36-2 & 757 & 338 & 560 & 265 & 493 \\
\hline M11-YrSP-2 & 340 & 181 & 228 & 129 & 266 \\
\hline M11-Yr76-1 & 140 & 78 & 70 & 44 & 110 \\
\hline M11-Yr76-3 & 243 & 125 & 144 & 83 & 189 \\
\hline M11-Yr43 & 89 & 59 & 6 & 6 & 65 \\
\hline M11-Yr44 & 76 & 46 & 9 & 9 & 49 \\
\hline M11-Yr1-1 & 118 & 60 & 10 & 10 & 67 \\
\hline M11-Yr8 & 55 & 30 & 9 & 9 & 38 \\
\hline M11-Yr31 & 69 & 37 & 7 & 7 & 41 \\
\hline Total & 1895 & 564 & 1059 & 401 & 731 \\
\hline
\end{tabular}

Four effector motifs, RXLR, $[\mathrm{R} / \mathrm{K} / \mathrm{H}] \mathrm{x}[\mathrm{L} / \mathrm{M} / \mathrm{I} / \mathrm{F} / \mathrm{Y} / \mathrm{W}] \mathrm{x}$, $[\mathrm{L} / \mathrm{I}] \mathrm{xAR}$ and $[\mathrm{Y} / \mathrm{F} / \mathrm{W}] \mathrm{xC}$, were found in nineteen putative effectors. Except for PS_11-281_00015631, all these effector candidates contained [Y/F/W] $\mathrm{xC}$ and/or RXLRLike motifs. All the motifs were found within $100 \mathrm{bp}$ from $\mathrm{N}$ terminal of each candidate (Table 5, Table 6). Subcellular localizations of the putative effectors in Pst were predicted using software WoLF_PSORT. The putative SPs effectors were predicted to be localized mainly in the extracellular spaces of the pathogen (Additional file 2: Fig. S6A), whereas the putative non-SP proteins highly associated with avirulence were predicted to be mostly situated in the nuclei of the pathogen (Additional file 2: Fig. S6B).
When the two groups were put together, the majority of gene products were located in the extracellular (47\%) and nuclear (29\%) spaces of the pathogen (Additional file 2: Fig. S6C). The subcellular localizations effectors inside host plant cells during infection were also predicted. Different from the SP effector candidates (Additional file 2: Fig. S7A), the non-SP candidate products were more likely to target at mitochondria (Additional file 2: Fig. S7B). When the two groups were put together, apoplasts (40\%) and nuclei (31\%) in host cells are the major targets for the candidate gene products during the process of infection, followed by chloroplasts (16\%) and mitochondria (13\%) (Additional file 2: Fig. S7C). 
Table 4 Numbers of associated genes, associated genes with signal peptides, SP genes without transmembrane helices (TH), and genes highly associated to avirulence (Avr) genes

\begin{tabular}{|c|c|c|c|c|}
\hline Avr & No. of & No. of associated genes & No. of associated & No. of highly \\
\hline gene & associated genes ${ }^{a}$ & with signal peptides ${ }^{b}$ & SP genes ${ }^{c}$ & associated genes ${ }^{\mathrm{C}}$ \\
\hline AvYri & 62 & 2 & 1 & 0 \\
\hline AvYr6 & 129 & 9 & 9 & 1 \\
\hline AvYrT & 121 & 11 & 10 & 1 \\
\hline AvYro & 27 & 1 & 1 & 4 \\
\hline AvYrg & 83 & 3 & 2 & 2 \\
\hline AvYr10 & 70 & 3 & 3 & 0 \\
\hline AvYri7 & 54 & 3 & 3 & 0 \\
\hline AvYr24 & 35 & 1 & 1 & 1 \\
\hline AvYr27 & 149 & 11 & 10 & 4 \\
\hline AvYr32 & 79 & 4 & 4 & 1 \\
\hline AvYr43 & 100 & 7 & 6 & 0 \\
\hline AvYr44 & 58 & 6 & 5 & 0 \\
\hline AvYr76 & 48 & 1 & 1 & 0 \\
\hline AvYrExp2 & 76 & 4 & 3 & 0 \\
\hline AvYrSP & 117 & 7 & 7 & 4 \\
\hline AvYrTr1 & 45 & 6 & 6 & 0 \\
\hline Total $^{\mathrm{e}}$ & 754 & 54 & 48 & 17 \\
\hline
\end{tabular}

${ }^{a}$ Associated genes to each Avr gene were selected with the $P$ value $\leq 0.05$ of output files using the GAPIT program

${ }^{\mathrm{b}}$ Signal peptides were detected from associated genes using SignalP 5.0 program

'Proteins of associated genes with signal peptides and without transmembrane helices were considered as SP genes

${ }^{\mathrm{d}}$ Associated genes to Avr genes with the $P$ value $\leq 0.001$ were considered as highly associated genes. Highly associated genes include 14 Non-SP genes and 3

SP genes

${ }^{\mathrm{e}}$ One gene can be associated with multiple Avr genes, so the total number of genes is not equal to the summation of associated genes from each Avr gene

\section{Discussion}

It is well-known that mutation is the ultimate source causing genetic variation, resulting in the generation of new alleles and genotypes [50]. The novelty of the present study is that we developed the mutants from EMS mutagenesis and identified the mutation sites throughout the genome, which led to identification of $A v r$ effector gene candidates. We expanded the research to the genomic analyses from the previous studies on mutant development and characterization of mutant isolates using virulence testing and molecular markers [10], as well as sequencing the progenitor isolate [49]. By genome sequencing of 30 mutant isolates and comparing with the wild-type isolate genome as the reference to find mutated genes, association analyses and effector characterization, we identified 62 Pst effectors with certain levels of high-confidence.

The high-quality assembly and annotation of progenitor isolate genome is the foundation for variation calling. To ensure the premium level of the reference genome, the wild-type isolate was sequenced using both Illumina and PacBio sequencing platforms [49]. The annotation was fulfilled with the help of transcript data retrieved from RNAseq from different time points. The assessment of completeness showed the high-level of assembly and annotation. In the present study, variant callings were implemented by aligning mutant sequences to the reference genome. We only selected C/G-to-T/A mutations from the variants since a plenitude of EMS mutagenesis studies demonstrated that EMS largely makes $\mathrm{C}$ to $\mathrm{T}$ and $\mathrm{G}$ to $\mathrm{A}$ transitions. Previous studies reported a frequency of $92 \%$ G/Cto-A/T transitions observed in Caenorhabditis elegans [51], $100 \%$ in Drosophila melanogaster [52] and 99\% in Arabidopsis [11]. EMS mutagenesis on other non-model organisms, such as legume [15], rice and wheat [16] and tomato [53], also indicated that EMS induced a biased spectrum of G/C-to-A/T transitions. Thus, the other types of mutations were filtered out in this study, which is the same strategy used on the mutation screening work on Arabidopsis [54], tomato [55], and fungal pathogen Pgt [20].

In the genomic studies of Pst, most assembled genomes generated a single set of contigs regardless of dikaryotic spore stages. Until recent years, four published genomes of $P$. striiformis were assembled into primary contigs and haplotigs $[36,38,48]$. Haplotigs were assembled from divergent regions, which contained SNPs and structural variants, in comparison with the primary contigs [56]. Assembled haplotigs tend to be more fragmented and 
Table 5 Characterization of 48 Avr effector candidates of Puccinia striiformis f. sp. tritici derived from secreted protein genes

\begin{tabular}{|c|c|c|c|c|c|c|c|c|c|c|}
\hline \multirow{2}{*}{$\begin{array}{l}\text { Avr } \\
\text { candidate }\end{array}$} & \multirow{2}{*}{$\begin{array}{l}\text { Associated } \\
\text { Avr gene }\end{array}$} & \multirow{2}{*}{$\begin{array}{l}\mathrm{SPL}^{\mathrm{b}} \\
\%\end{array}$} & \multicolumn{2}{|l|}{ EffectorP } & \multirow{2}{*}{$\begin{array}{l}\mathrm{AA}^{\mathrm{d}} \\
\text { length }\end{array}$} & \multirow{2}{*}{$\begin{array}{l}C^{e} \\
\%\end{array}$} & \multirow[b]{2}{*}{ Conservation } & \multirow{2}{*}{$\begin{array}{l}\text { Polymorphic }{ }^{f} \\
\text { in Pst }\end{array}$} & \multirow{2}{*}{$\begin{array}{l}\text { Pfam } \\
\text { Family }\end{array}$} & \multirow[t]{2}{*}{ Motifg } \\
\hline & & & Effector & $\%^{c}$ & & & & & & \\
\hline PS_11-281_00004726 & 1 & 99.8 & Yes & 67.4 & 115 & 5.22 & Ps. specific & Yes & & {$[Y / F / W] \times C$} \\
\hline PS_11-281_00016865 & 6 & 99.8 & Yes & 88.5 & 115 & 6.09 & $P^{h}$. specific & Yes & & {$[\mathrm{Y} / \mathrm{F} / \mathrm{W}] \times \mathrm{C}$} \\
\hline PS_11-281_00015631 & 7 & 99.7 & Yes & 94.5 & 133 & 6.02 & P. specific & Yes & & \\
\hline PS_11-281_00002472 & 7 & 99.8 & Yes & 84.7 & 153 & 3.92 & P. specific & Yes & & $\begin{array}{l}\text { RXLR-Like; } \\
{[Y / F / W] \times C}\end{array}$ \\
\hline PS_11-281_00009923 & 76 & 99.9 & Yes & 85.2 & 127 & 5.51 & Ps. specific & Yes & & {$[\mathrm{Y} / \mathrm{F} / \mathrm{W}] \times \mathrm{C}$} \\
\hline PS_11-281_haploid_00011016 & 17 & 99.7 & Yes & 94.5 & 133 & 6.02 & P. specific & Yes & & {$[Y / F / W] \times C$} \\
\hline PS_11-281_00011501 & $32, \mathrm{SP}$ & 67.7 & Yes & 57.4 & 307 & 4.56 & Ps. specific & Yes & & {$[Y / F / W] \times C$} \\
\hline PS_11-281_00002262 & 8 & 96.3 & No & 73.3 & 112 & 4.46 & Ps. specific & Yes & & $\begin{array}{l}\text { RXLR-Like; } \\
{[Y / F / W] \times C}\end{array}$ \\
\hline PS_11-281_00010750 & 27 & 97.5 & No & 88.1 & 506 & 3.56 & P. specific & Yes & & \\
\hline PS_11-281_00012402 & 7,27 & 95.7 & No & 51 & 140 & 0.00 & Ps. specific & Yes & & \\
\hline PS_11-281_00014479 & 7, 27, 43, Exp2 & 83.1 & No & 95.7 & 186 & 3.23 & $\begin{array}{l}\text { Basidiomycetes } \\
\text { orthologs }\end{array}$ & Yes & & \\
\hline PS_11-281_haploid_00010301 & 6 & 97.5 & No & 95.7 & 524 & 3.82 & P. specific & Yes & & \\
\hline PS_11-281_00009924 & $\operatorname{Tr} 1$ & 81.5 & No & 95.7 & 1371 & 0.58 & P. specific & Yes & & \\
\hline PS_11-281_00009841 & 44 & 98.8 & No & 91.5 & 783 & 0.13 & P. specific & Yes & & \\
\hline PS_11-281_00009866 & 17 & 60.9 & No & 88.8 & 406 & 1.23 & Ps. specific & Yes & & \\
\hline PS_11-281_00013192 & 27 & 97.1 & No & 92.1 & 627 & 0.64 & Ps. specific & Yes & & \\
\hline PS_11-281_00014125 & SP & 98.2 & No & 96.9 & 329 & 3.65 & ji & Yes & & \\
\hline PS_11-281_00016661 & 43, Exp2, SP & 92.5 & No & 96.9 & 574 & 0.35 & Ps. specific & Yes & & \\
\hline PS_11-281_00003286 & 27 & 89.2 & No & 92.6 & 250 & 0.80 & P. specific & Yes & & RXLR-Like \\
\hline PS_11-281_00011083 & $6, \mathrm{SP}$ & 96.3 & No & 99 & 936 & 1.60 & P. specific & Yes & & \\
\hline PS_11-281_00014412 & $6, \mathrm{SP}$ & 84.6 & No & 95.6 & 696 & 1.58 & P. specific & Yes & & \\
\hline PS_11-281_haploid_00003208 & 10,32 & 79.8 & No & 91.2 & 468 & 0.21 & P. specific & Yes & & \\
\hline PS_11-281_haploid_00006920 & 6 & 85.7 & No & 99.1 & 524 & 1.15 & P. specific & Yes & & {$[\mathrm{L} / \mathrm{I}] \times \mathrm{AR}$} \\
\hline PS_11-281_haploid_00006507 & 6 & 99.0 & No & 95.4 & 589 & 0.85 & P. specific & Yes & & RXLR-Like \\
\hline PS_11-281_haploid_00002163 & 9,17 & 60.9 & No & 93.4 & 443 & 1.81 & Ps. specific & Yes & & \\
\hline PS_11-281_haploid_00004265 & 6 & 57.8 & No & 94.9 & 1325 & 4.53 & Ps. specific & Yes & PF00840.20 & \\
\hline PS_11-281_haploid_00002648 & $7, \operatorname{Tr} 1$ & 66.9 & No & 97.6 & 812 & 0.86 & P. specific & Yes & & \\
\hline PS_11-281_00004920 & $7,27,43, \operatorname{Tr} 1$ & 72.2 & No & 86 & 323 & 0.93 & / & Yes & & RXLR-Like \\
\hline PS_11-281_00014999 & 27 & 96.6 & No & 93.6 & 1029 & 0.29 & / & Yes & & \\
\hline PS_11-281_00001788 & 27 & 66.8 & No & 98.9 & 1989 & 1.16 & P. specific & Yes & PF03033.20 & $\begin{array}{l}\text { RXLR-Like; } \\
{[Y / F / W] \times C}\end{array}$ \\
\hline PS_11-281_00011666 & $10,24,27, \operatorname{Tr} 1$ & 92.0 & No & 95.1 & 1165 & 0.09 & P. specific & Yes & PF02358.16 & \\
\hline PS_11-281_00011857 & $\mathrm{SP}$ & 99.8 & No & 98.8 & 760 & 1.48 & / & Yes & & RXLR-Like \\
\hline PS_11-281_00003160 & 43 & 97.5 & No & 99.1 & 993 & 0.91 & P. specific & Yes & PF00450.22 & \\
\hline PS_11-281_00006608 & 27 & 60.2 & No & 97.3 & 550 & 2.00 & P. specific & Yes & PF01575.19 & \\
\hline PS_11-281_00012767 & 7, 43, Exp2 & 92.2 & No & 94.3 & 1933 & 0.16 & / & Yes & & \\
\hline PS_11-281_00003315 & 10,32 & 99.7 & No & 90.5 & 400 & 1.25 & P. specific & Yes & PF02156.15 & \\
\hline PS_11-281_haploid_00005879 & 44 & 87.1 & No & 98.9 & 670 & 0.60 & / & Yes & & \\
\hline PS_11-281_00011495 & 6 & 92.8 & No & 95.6 & 1206 & 1.16 & / & Yes & PF01735.18 & \\
\hline PS_11-281_00013988 & $\operatorname{Tr} 1$ & 62.3 & No & 78.9 & 416 & 0.48 & / & Yes & PF12776.7 & \\
\hline PS_11-281_00003121 & $7,43,44$ & 65.0 & No & 97.6 & 1498 & 0.93 & $\begin{array}{l}\text { Basidiomycetes } \\
\text { orthologs }\end{array}$ & Yes & PF01239.22 & \\
\hline
\end{tabular}


Table 5 Characterization of 48 Avr effector candidates of Puccinia striiformis f. sp. tritici derived from secreted protein genes (Continued)

\begin{tabular}{|c|c|c|c|c|c|c|c|c|c|c|}
\hline \multirow{2}{*}{$\begin{array}{l}\text { Avr } \\
\text { candidate }\end{array}$} & \multirow{2}{*}{$\begin{array}{l}\text { Associated } \\
\text { Avr gene }\end{array}$} & \multirow{2}{*}{$\begin{array}{l}\mathrm{SPL}^{\mathrm{b}} \\
\%\end{array}$} & \multicolumn{2}{|c|}{ EffectorP } & \multirow{2}{*}{$\begin{array}{l}A A^{d} \\
\text { length }\end{array}$} & \multirow{2}{*}{$\begin{array}{l}\mathrm{C}^{\mathrm{e}} \\
\%\end{array}$} & \multirow[b]{2}{*}{ Conservation } & \multirow{2}{*}{$\begin{array}{l}\text { Polymorphic } \\
\text { in Pst }\end{array}$} & \multirow{2}{*}{$\begin{array}{l}\text { Pfam } \\
\text { Family }\end{array}$} & \multirow[t]{2}{*}{ Motif9 } \\
\hline & & & Effector & $\%^{c}$ & & & & & & \\
\hline PS_11-281_00005153 & $\operatorname{Tr} 1$ & 79.2 & No & 93.9 & 1524 & 0.46 & / & Yes & PF01369.20 & RXLR \\
\hline PS_11-281_00013742 & 7 & 97.6 & No & 94 & 406 & 0.74 & / & Yes & PF05890.12 & \\
\hline PS_11-281_00012902 & 7 & 99.5 & No & 97.8 & 507 & 0.79 & / & Yes & PF01565.23 & \\
\hline PS_11-281_00012863 & $9, \mathrm{SP}$ & 55.0 & No & 88.2 & 848 & 1.06 & / & Yes & PF07217.11 & \\
\hline PS_11-281_haploid_00007789 & 6 & 56.5 & No & 97.1 & 649 & 0.92 & / & Yes & PF09118.11 & \\
\hline PS_11-281_haploid_00010769 & 44 & 91.0 & No & 88.1 & 452 & 1.33 & $\begin{array}{l}\text { Basidiomycetes } \\
\text { orthologs }\end{array}$ & Yes & PF00704.28 & \\
\hline PS_11-281_haploid_00005482 & 32 & 99.9 & No & 99 & 630 & 0.95 & / & Yes & PF09286.11 & \\
\hline PS_11-281_haploid_00011285 & 44 & 60.6 & No & 98.7 & 541 & 1.11 & / & Yes & PF00135.28 & \\
\hline
\end{tabular}

${ }^{a}$ Associated Avr gene included 1, 6, 7, 8, 9,10,17, 24, 27, 32, 43, 44, 76, Exp2, SP and Tr1, which are the abbreviations for the AvYr1, AvYr6, AvYr7, AvYr8, AvYr9, AvYr10, AvYr17, AvYr24, AvYr27, AvYr32, AvYr43, AvYr44, AvYr76, AvYrExp2, AvYrSP and AvYrTr1, respectively

${ }^{\mathrm{b}} \mathrm{SPL}=$ signal peptide likelihood

'The percentage indicates the probability of the protein to be effector or non-effector based on the machine learning evaluation in EffectorP

${ }^{\mathrm{d}} A A$ Amino acid

${ }^{\mathrm{e}} \mathrm{C}$ Cysteine

${ }^{\mathrm{f}}$ The polymorphisms of effector candidates were determined by searching homologous sequences from publicly available protein database in Pst

${ }^{9}$ Motifs RxLR, RxLR-like ([R/K/H]x[L/M/I/F/Y/W]x), YxSL[R/K], [L/I] XAR, [R/K]CxxCx12H, [R/K]VY[L/I] R, G[I/F/Y][A/L/S/T]R and [Y/F/W]xC were searched for motifs in the effector candidates

${ }^{\mathrm{h}} \mathrm{P}$ Puccinia

i/ No conservation detected in the Fungi Kingdom

cannot be simply considered as the genome for the other nucleus. However, omission of haplotigs in the genome analysis may miss some important information. Due to the lack of phased assembles as reference genomes, previous association studies to identify effector candidates on $P s t$ and $P t$ focused only on primary contigs $[39,40]$. In the present study, we detected SNPs and Indels from both primary scaffolds and haplotigs and conducted association analysis using all identified variants.

In the present study, 67,913 SNPs and 12,886 Indels were detected from the primary scaffolds while 24,796 SNPs and 15,468 Indels from the haplotigs. Thus, the frequency of mutation was $6.40 \times 10^{-4}$ in term of SNPs and $1.96 \times 10^{-4}$ in term of Indels. These values are
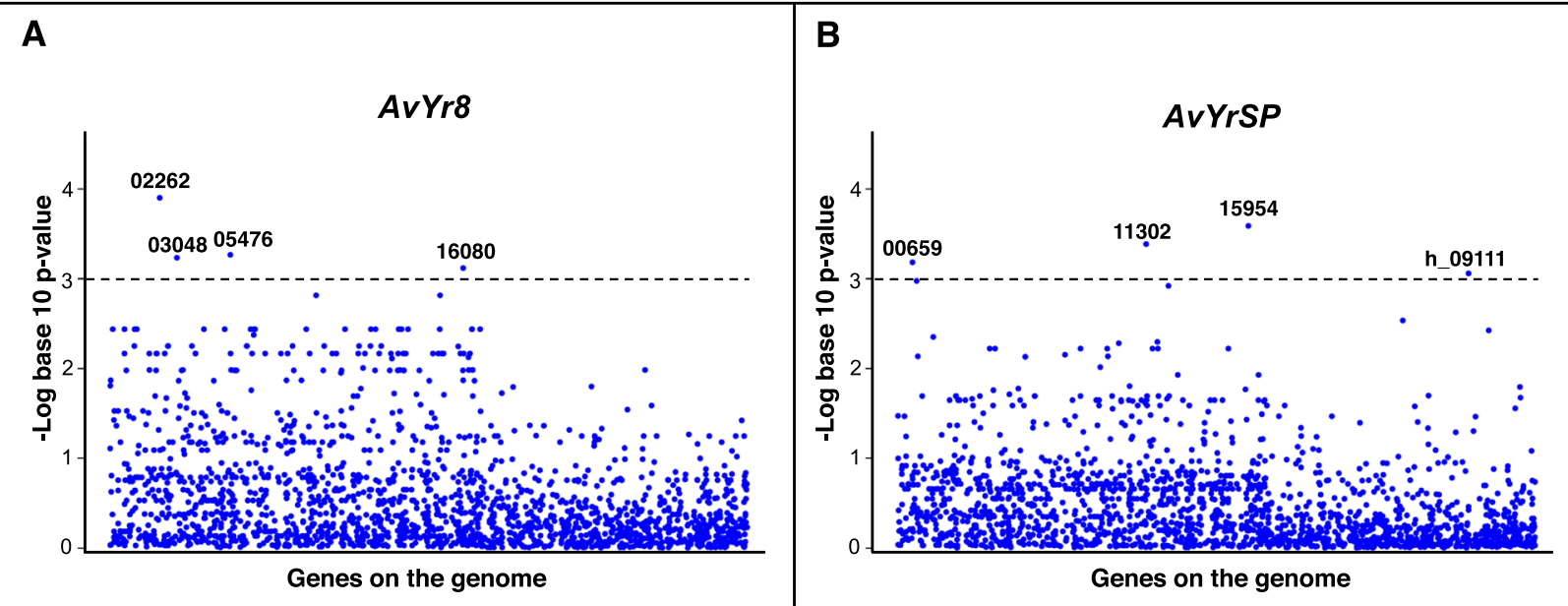

Fig. 5 Examples of Manhattan plots in scaffolds displaying association between genes from isolate 11-281 and Avr genes of Puccinia striiformis $\mathrm{f}$. sp. tritici. The $X$ axis shows genes on the genome and $Y$ axis indicates $-\log _{10}$ ( $P$ value). a: Genes are highly associated with AvYr8. 02262, 03048, 05476 and 16,080 are PS_11-281_00002262, PS_11-281_00003048, PS_11-281_00005476 and PS_11-281_00016080, which are associated to AvYr8 with $P$ value 1.25E-04, 5.83E-04, 5.40E-04 and 7.63E-04, respectively. b: Genes are highly associated with AvYrSP. 00659, 11,302, 15,954 and h_09111 denote PS_11-281_00000659, PS_11-281_00011302, PS_11-281_00015954 and PS_11-281_haploid_00009111, respectively, which are associated to AvYrSP with $P$ value $6.53 \mathrm{E}-04,4.11 \mathrm{E}-04,2.58 \mathrm{E}-04$ and $8.74 \mathrm{E}-04$, respectively 
Table 6 Characterization of 14 Avr effector candidates of Puccinia striiformis f. sp. tritici from non-secreted protein genes

\begin{tabular}{|c|c|c|c|c|c|c|c|c|c|c|}
\hline \multirow{2}{*}{$\begin{array}{l}\text { Avr } \\
\text { candidate }\end{array}$} & \multirow{2}{*}{$\begin{array}{l}\text { Associated } \\
\text { Avr gene }\end{array}$} & \multirow{2}{*}{$\begin{array}{l}S P L \\
\%\end{array}$} & \multicolumn{2}{|l|}{ EffectorP } & \multirow{2}{*}{$\begin{array}{l}\text { AA } \\
\text { length }\end{array}$} & \multirow{2}{*}{$\begin{array}{l}\mathrm{C} \\
\%\end{array}$} & \multirow[b]{2}{*}{ Conservation } & \multirow{2}{*}{$\begin{array}{l}\text { Polymorphic } \\
\text { in Pst }\end{array}$} & \multirow{2}{*}{$\begin{array}{l}\text { Pfam } \\
\text { Family }\end{array}$} & \multirow[t]{2}{*}{ Motif } \\
\hline & & & Effector & $\%$ & & & & & & \\
\hline PS_11-281_00005476 & AvYr8 & 0.8 & No & 50.5 & 381 & 3.9 & Ps. specific & Yes & & {$[Y / F / W] \times C$} \\
\hline PS_11-281_00009555 & AvYr9 & 0.1 & No & 99.1 & 590 & 3.2 & P. specific & Yes & & \\
\hline PS_11-281_00015954 & AvYrSP & 1.6 & No & 87.7 & 283 & 0.4 & P. specific & Yes & & \\
\hline PS_11-281_00005142 & AvYr27 & 0.4 & No & 99 & 902 & 2.8 & Ps. specific & Yes & & {$[Y / F / W] \times C$} \\
\hline PS_11-281_haploid_00011106 & AvYr6 & 0.1 & No & 95.9 & 564 & 2.3 & / & Yes & & \\
\hline PS_11-281_00014472 & AvYr7 & 0.1 & No & 96.8 & 612 & 1.8 & / & Yes & & {$[\mathrm{L} / \mathrm{I}] \times A R$} \\
\hline PS_11-281_00000659 & AvYrSP & 0.3 & No & 73.3 & 287 & 0.7 & / & Yes & PF14223.6 & \\
\hline PS_11-281_00003048 & AvYr8 & 0.1 & No & 95.6 & 1363 & 0.4 & / & Yes & PF09766.9 & \\
\hline PS_11-281_00016080 & AvYr8 & 0.1 & No & 99.1 & 1415 & 1.4 & / & Yes & PF07727.14 & \\
\hline PS_11-281_00000903 & AvYrg & 0.5 & No & 99.1 & 527 & 0.8 & $\begin{array}{l}\text { Basidiomycetes } \\
\text { orthologs }\end{array}$ & Yes & PF00617.19 & \\
\hline PS_11-281_haploid_00002745 & AvYr24; AvYr32 & 0.1 & No & 99.1 & 611 & 1.6 & / & Yes & PF07690.16 & \\
\hline PS_11-281_00003874 & AvYr27 & 0.1 & No & 99.1 & 1087 & 2.3 & / & Yes & PF00899.21 & {$[Y / F / W] \times C$} \\
\hline PS_11-281_00011302 & AvYrSP & 0.1 & No & 97.1 & 1222 & 2.1 & / & Yes & PF05699.14 & {$[Y / F / W] \times C$} \\
\hline PS_11-281_haploid_00009111 & AvYrSP & 0.1 & No & 99.1 & 823 & 2.4 & / & Yes & PF00648.21 & \\
\hline
\end{tabular}

slightly higher but comparable to previously reported $10^{-4}$ to $10^{-5}$ frequencies of EMS mutation $[16,51,57]$. As the Pst mutant isolates were obtained through selection based on moderate to severe changes in virulence, such strong phenotypic selection increased the possibility of detecting variants throughout the pathogen genome. Additionally, the differences in mutation rate may due to the differences in organisms and duration or doses of EMS treatment. The high proportion (70.92 to 99.07\%) of mutation SNPs was heterozygous (Table 1). This can be explained by the property of Pst and EMS mutagenesis. i) The two nuclei in Pst urediniospores

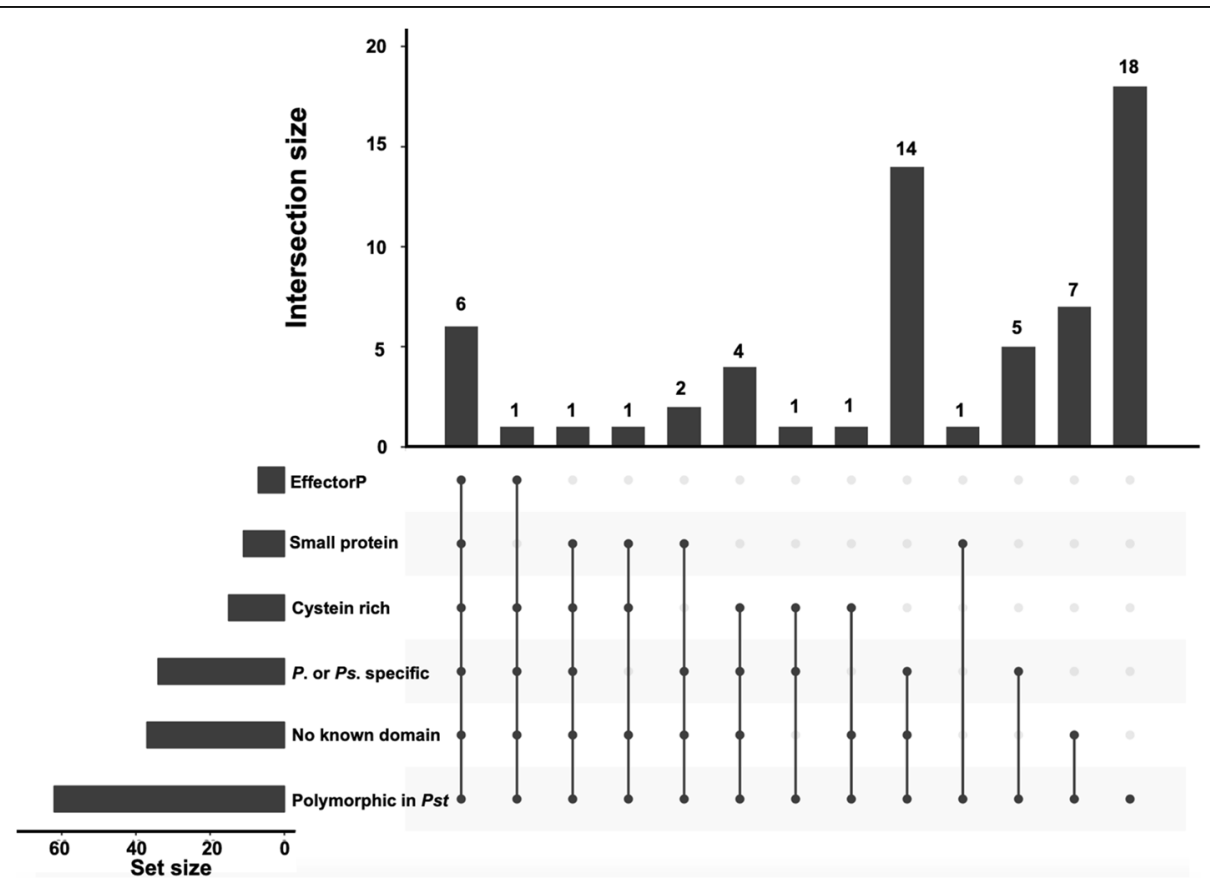

Fig. 6 Characterization of 62 Puccinia striiformis f. sp. tritici Avr effector candidates in Upset plots. Six criteria were used for characterizing the effector candidates. The set size indicates the number of candidates meet the requirement for each criterion. The intersection size shows the number of candidates meeting one or more criteria 


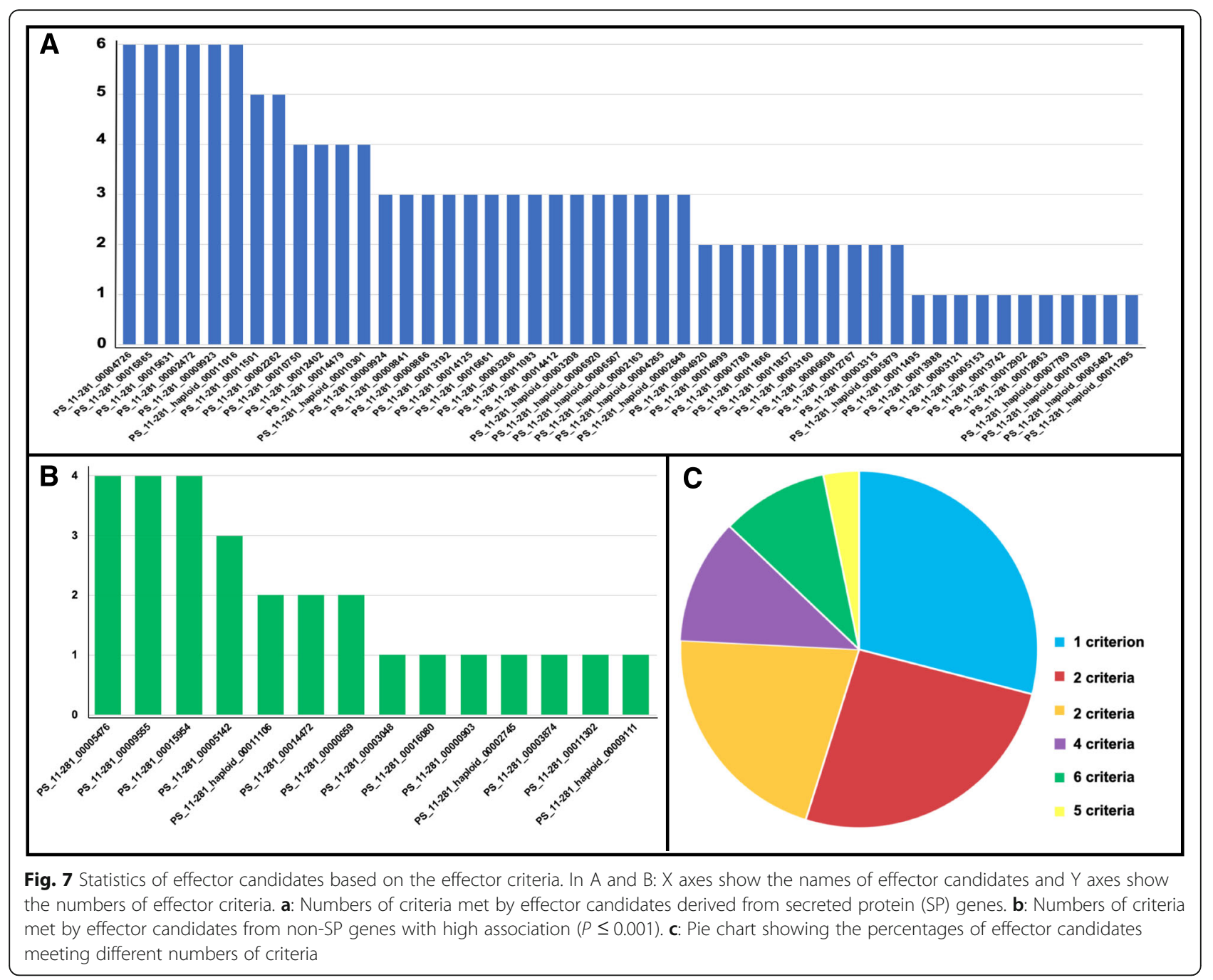

were found to be highly heterozygous in many isolates [37, 39, 58, 59]. ii) Previous studies observed Pst isolates with a low virulence spectrum tended to be highly heterozygous $[39,60]$. The narrow virulence spectrum of Pst 11-281 is likely related to its high heterozygosity. iii) The possibility of mutagenesis occurs on the two nuclei to generate homozygous SNPs are much lower than that of producing heterozygous SNPs. Therefore, it is not surprising that heterozygous SNPs took a high proportion of the total EMS-induced SNPs. The number of SNPs and Indels varied greatly among the Pst scaffolds. For example, more SNPs were found in primary scaffolds 143, 180, 133 and 277 with the SNP density $>6000 \mathrm{SNP} / \mathrm{Mb}$, whereas no SNPs were found in primary scaffolds 48,149 and 343. Similarly, the most intensive Indels were found in primary scaffold 370 , but no Indels were detected in primary scaffolds 48, 149 and 343 (Fig. 2, Additional file 1: Table S3). The variants densities indicated that mutations occurred from the selected 30 mutant isolates were not randomly distributed, which allowed us to identify genes with SNPs and/or Indels associated to all possible avirulence/virulence phenotypes.

We conducted association analysis between EMSinduced variants and the avirulence/virulence phenotypes based on the IT data of the 30 mutant isolates on each of the $18 \mathrm{Yr}$ single-gene lines used to differentiate Pst races [10, 48, 61]. SNPs annotated with high and moderate effects were believed to be deleterious, which consisted of splice, missense, start loss and stop gain variants. Likewise, Indels annotated with high and moderate effects were regarded as deleterious Indels, including frameshift, splice, conserved and disruptive inframe Indels, stop codon gained and lost, start codon and exon loss and bidirectional gene fusions. We noticed that deleterious effects counted for 4.2 and $4.6 \%$ of the total effects from SNPs and Indels, respectively. Fourteen genes involved in deleterious SNPs and Indels with high association $(P \leq 0.001)$ regardless $\mathrm{SPs}$ were identified as effectors or not from a different perspective. Taking association analysis and EMS-induced variant annotation 


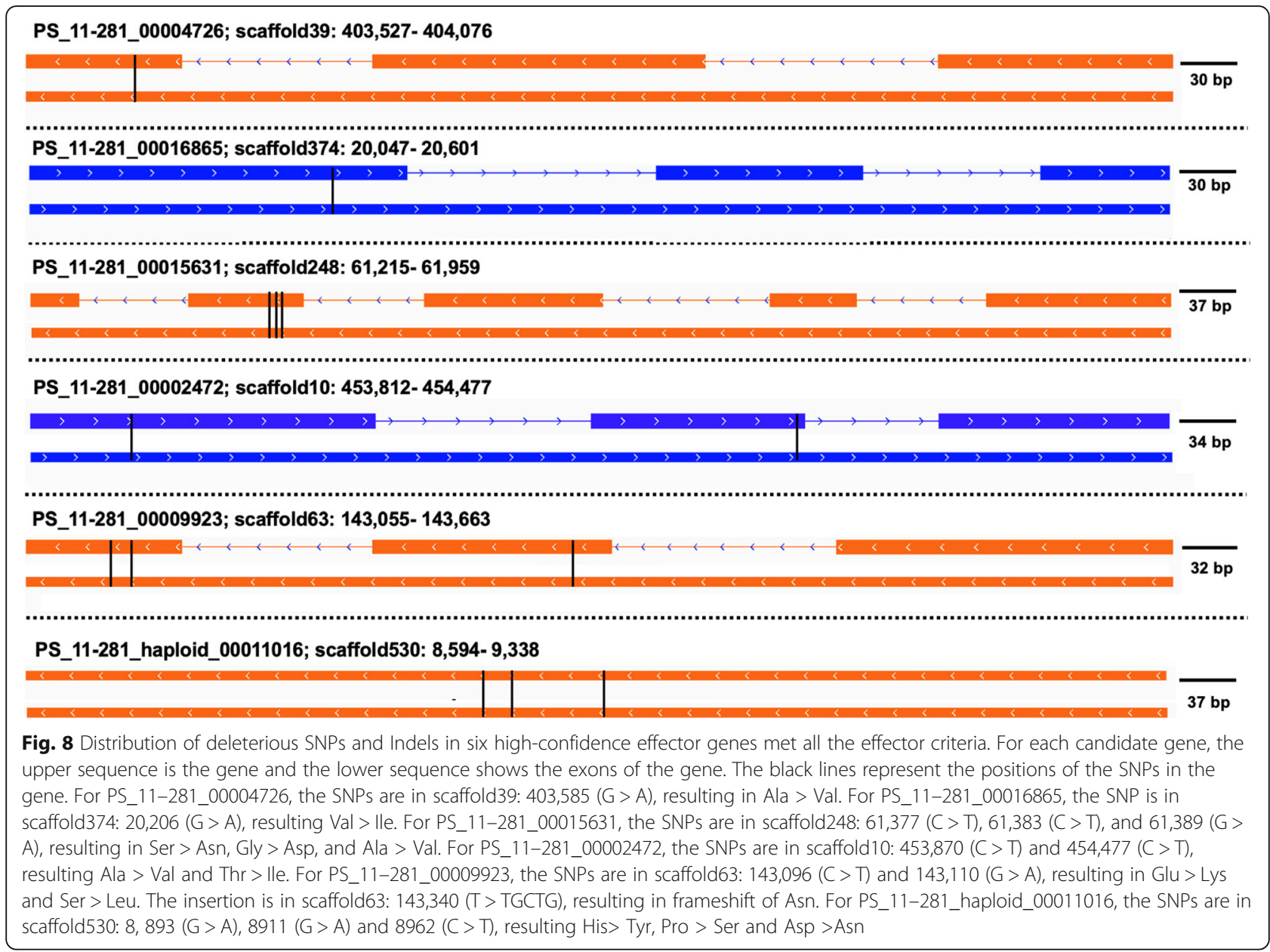

into consideration, a total of 62 genes, including 48 SPs and 14 non-SPs, obtained from the present study were considered to be $A v r$ candidates with various degrees of confidence.

There is no a one-size-fits-all standard to predict effectors, but the features of most known fungal effectors are useful for assessing effectors. Effectors have been studied in both biotrophic and necrotrophic fungal pathogens [62-65]. The pipelines to determine rust effector candidates were accomplished by Saunders et al. [41] and Sperschneider et al. [42, 43]. These pipelines are developed based on the observed properties of known effectors in rust fungi, including secreted, small size, cysteine rich and rust-specific. In the present study, we firstly evaluated the 48 Avr candidates of SPs based on the six criteria and found them met at least one of the criteria. Eight of the candidates were satisfied with at least five criteria and therefore, considered as high-confidence effector candidates. It is noted that not all the identified avirulence genes encoding SPs. For example, Magnaporthe oryzae (M. oryzae) Avr gene ACE1 is predicted to be non-secreted and localizes in the cytoplasm of appressoria [66]. Therefore, the 14 non-SP candidates we obtained from variants with high associations to avirulence were evaluated following the same effector standards.

Previous studies showed several cloned $A v r$ effectors by meeting the requirements in effector prediction. For example, the Pgt effector gene AvrSr35 encodes a 578amino acid protein [20], which is greater than the 300 amino acids threshold. The Bgh effector BEC1019 was escaped from the detection with the EffectorP program [67]. Thus, the candidates met more criteria have a higher priority in the future functional verification, but the candidates received relatively low confidence values should not been discarded.

For all the identified effector candidates, sixteen of them were derived from haplotigs of the wild-type isolate, including PS_11-281_haploid_00011016 with a high-degree confidence. Therefore, studies on haplotigs made a significant contribution to identification of effectors in Pst. Among all 62 candidates identified, 46 each are associated with one $A v r$ locus and 16 each associated to multiple $A v r$ loci. For example, the six candidates 
(PS_11-281_00004726, PS_11-281_00016865, PS_11281_00015631, PS_11-281_00002472, PS_11-281_ 00009923 and PS_11-281_haploid_00011016) that met all six criteria each were associated with a single Avr locus (Avr1, Avr6, Avr7, Avr7, Avr76 and Avr17, respectively). This kind of Avr candidates corresponding to only one $R$ gene fits the gene-for-gene hypothesis [22]. Therefore, those genes can be considered as Avr1, Avr6, Avr7, Avr76 and Avr17 candidates. In a different case, PS_11-281_00011501, which met five of the six criteria, was associated with both $A v Y r 32$ and $A v Y r S P$. Interestingly, the avirulent/virulent phenotypes of these two genes are highly correlated among the Pst races (6, $60,61)$. The shared candidate gene and correlated phenotypes indicate that $A v Y r 32$ and $A v Y r S P$ are located in a small genomic region, or they are the same avirulence gene, but corresponding to both wheat resistance genes $Y r 32$ and $Y r S P$. It is not unusual in rust fungal effectors. In the cloned effectors of M. lini, AvrL567 corresponds to flax resistance genes $L 5, L 6$ and $L 7$ [28]; and the Avr protein of AvrM14 is recognized by both $M 1$ and $M 4$ resistance proteins in flax [18]. The similar phenomenon was also found in the Leptosphaeria maculans effector gene AvrLm4-7, which triggers resistance responses to Rlm4 and $R \operatorname{lm} 7$ [68]. The observations of one effector gene correlated to multiple Avr genes could also be explained by linkages of $A v r$ loci. Using a sexually reproduced Pst segregating population, Yuan et al. [9] mapped several $A v r$ genes to a single chromosomal region.

Effector candidate PS_11-281_00011501 did not meet all the six criteria, but its 307-amino acid length was very close to the threshold of 300 amino acids. Effectors with amino acids greater than 300 were also observed in Pgt effector AvrSr35 [20] and M. lini effector AvrM [69]. PS_11-281_00002262 fit five criteria but did not pass through program EffectorP 2.0. Similar result was reported for Bgh effector CSEP0105, which was also a small size and cysteine-rich protein but failed to be identified as an effector by the EffectorP program [67].

Previous studies failed to identify conserved sequence motifs like oomycetes motif RxLR in fungal effectors [44]. However, few studies found some motifs within a species $[46,47]$. In the present study, we identified four motifs in nineteen effector candidates (Table 5, Table 6). It is worth mentioning that motif $[\mathrm{Y} / \mathrm{F} / \mathrm{W}] \mathrm{xC}$ was found within $100 \mathrm{bp}$ from the cleavage sites of seven putative effectors with high-degree confidence. Motif $[\mathrm{Y} / \mathrm{F} / \mathrm{W}] \mathrm{xC}$ has been detected in SPs in Pgt $[46,47]$ and predicted Pst candidates [39]. Due to the limited number of cloned effectors in the Puccinia species, we could not determine whether $[\mathrm{Y} / \mathrm{F} / \mathrm{W}] \mathrm{xC}$ is a conserved motif of effectors in the genus Puccinia. RXLR and RXLR-like motifs, which have been commonly found in oomycetes effector, were detected in eight Pst avirulence gene candidates in the present study. Also, motif [L/I]xAR previously reported from $M$. oryzae effectors was detected in two of the Pst avirulence gene candidates. It is still not clear whether these effector motifs from oomycetes and ascomycetes are related to avirulence genes in Puccinia of basidiomycetes. This information is important in characterizing effectors and understanding evolutionary mechanisms of plant pathogenic fungi and oomycetes. Functional verification of more effector candidates in Puccinia species and other fungi or oomycetes, conserved motifs could be identified in the near future.

Effectors can be classified into apoplastic, cytoplasmic and nuclear categories based on their subcellular localization and action inside hosts [70]. Since software LOCALIZER can only predict the location of chloroplast, mitochondria and nuclei [71], those with their targets unpredictable were considered as apoplastic effectors. In the present study, 25 avirulence gene candidates were predicted to be apoplastic effectors, with $\mathrm{pu}$ tative functions of inhibiting host proteases and peroxidases. Nineteen effectors were classified as nuclear effectors, which were predicted to suppress the host defense system from the upstream by disturbing gene transcriptions related to host defense. Thirteen effectors were regarded cytoplasmic, which may influence host defense signaling and metabolism by targeting related proteins. Five effectors (PS_11-281_00001788, PS_11281_00013988, PS_11-281_00013742, PS_11-281_ 00006608 and PS_11-281_haploid_00003208) were presumed to possess dual functions in both cytoplasm and nucleus, as reported in other fungi [70].

Our study identified 62 Pst Avr candidates through comparative genomics and association analyses. With the identification of more effectors in Puccinia species in recently years $[20,25,31,72]$, functional verification using RNA silencing and transient expression systems should be plausible approaches to identify Pst effectors. Confirmation of the roles of these effector candidates in the future studies is very likely to clone Avr genes in Pst, which should shed light on the mechanisms of interactions between the host and pathogen. Cloning Avr genes in the future are important for developing a new approach for quickly detecting Pst races in the field and for manipulating the evolution of effectors so as to develop resistance genes and control the disease in a more efficient way.

\section{Conclusions}

In the present study, we further studied 30 mutant isolates developed by EMS mutagenesis of isolate 11-281 of the least virulent race of Pst identified so far in the U.S. By genomic sequencing the wild-type isolate and the derived mutants, we aligned the sequences of the 
mutants with the wild-type isolate to determine sequence variants and identify $A v r$ gene candidates. The effects of EMS mutagenesis on Pst from the perspective of whole genome were summarized in this study. More importantly, by integrating the virulence data with EMSinduced polymorphisms, we identified 62 candidates for $A v r$ genes. In addition, we evaluated and characterized these effector candidates through various bioinformatics analyses and identified eight high-confidence candidates, six of which were meet all the effector criteria. The candidate genes will be used for the upcoming studies to verify their functions. Our study proved that mutagenesis in combination with whole genomic sequencing is a potent approach in identifying high-confidence Avr candidates in the obligate biotrophic fungus, leading to unravelling pathogen variation and cloning Avr effectors from the stripe rust pathogen in the future.

\section{Methods}

\section{Selection of mutant isolates}

Thirty mutant isolates were selected from those developed through EMS-mutagenesis of Pst isolate 11-281, representing PSTv-18, the least virulent race of Pst identified so far in the U.S. [48]. These isolates were developed and have been maintained by our stripe rust program in the Wheat Health, Genetics and Quality Research Unit of the US Department of Agriculture, Agricultural Research Service and the Department of Plant Pathology, Washington State University, Pullman, WA, the United States. The isolates were previously tested on the $18 \mathrm{Yr}$ single-gene lines used to differentiate Pst races [10]. The 30 isolates were selected based on their avirulence/virulence patterns on 16 of the $18 \mathrm{Yr}$ single gene lines on which they produced both avirulent and virulent reactions in relatively balanced ratios among the isolates.

\section{Sequencing of the reference genome and mutant isolates} The whole genome of the progenitor isolate (11-281) sequenced, assembled and annotated as previously reported [49], was used as a reference genome in this study. The assembled genome sequence of $P$. striiformis isolate 11-281 is available on GenBank under the accession number SBIN00000000. The version described in this article is version SBIN01000000. The raw data of isolate 11-281 used for this experiment has been submitted to NCBI with SRA study SRR8446446. Urediniospores of the 30 mutant isolates were collected from infected wheat plants grown in growth chambers, dried in a desiccator at $4{ }^{\circ} \mathrm{C}$ for about a week, and used for extracting genomic DNA using the cetyl trimethylammonium bromide $(\mathrm{CTAB})$ method with modifications as previously described [73]. The genomic DNA samples of the 30 mutant isolates were sequenced using the Illumina Hiseq 2000 technology by Novogene Corporation
(Sacramento, CA, U.S.A.). The raw data of the $30 \mathrm{mu}-$ tant isolates have been deposited in the NCBI under BioProject accession PRJNA587768 (containing SRA accessions SRR10413520 to SRR10413549) with the title "Puccinia striiformis f. sp. tritici strain:PST-mutants | isolate:PST-mutants_M11 Raw sequence reads".

\section{Sequence alignment and variant detection}

After examining the quality of raw paired-ends reads from Illumina sequencing using software FastQC version 0.11.6, the low-quality reads were filtered out using Trimmomatic version 0.36 [74]. The progenitor reference genome was indexed using Burrows-Wheeler Alignment (BWA) Tool version 0.7.17. Quality-checked sequences from the 30 mutant isolates were aligned to the reference genome using the BWA-mem algorithm with default options [75]. The SAM formatted file was obtained from alignment and converted to a BAM formatted file using the SAMtools version 1.9 view command. After cleaning unmapped reads, sorting, validating and removing duplicates with Picard tools version 2.18.11, the BAM file was indexed using SAMtools as the input for the Genome Analysis Toolkit (GATK) version 4.1.0.0 HaplotypeCaller to call variants. The GTAK HaplotypeCaller was used twice to call variants in the pipeline. In the first round of calling variants, only SNPs and Indels with a high degree of confidence were kept using VCFtools version 0.1.17 with the threshold value as following: --min-alleles 2 --max-alleles 2 --minQ 1000. The high-confidence SNPs and Indels were used as known variant sites to build a model of covariation, and then they were adjusted for the base quality scores on the basis of the model using BaseRecalibrator. The base quality scores were recalibrated using ApplyBQSR to generate recalibrated BAM files that served as input files for the second round variant calling using GTAK HaplotypeCaller. The SNPs and Indels were selected based on the parameters setting as: --minalleles 2 --max-alleles 2 --minQ 30 --min-meanDP 5 --max-meanDP 90 --max-missing 1. In addition, hardfiltering was performed to filter the variants and select the high-quality SNPs and Indels using VariantFiltration. The thresholds setting as: "QUAL $<0\|\mathrm{MQ}<40.00\|$ SOR $>4.000||$ QD $<2.00 \|$ FS $>60.000 \|$ MQRankSum $<-20.000||$ ReadPosRankSum $<-10.000$ || ReadPosRankSum $>10.000$ " in SNPs filtering and "QUAL $<0 \| \mathrm{MQ}<$ 40.00 || SOR $>10.000$ || QD $<2.00$ || FS $>200.000$ \| ReadPosRankSum <-20.000 || ReadPosRankSum > 20.000 || DP $>=20$ " in Indel filtering, which were recommended in the GATK "best practice" with modifications (https:// software.broadinstitute.org/gatk/best-practices/). SNPs were further filtered by selecting only $\mathrm{C}$ to $\mathrm{T}$ and $\mathrm{G}$ to $\mathrm{A}$ mutations since mutations caused by EMS had the strong CG to TA transition bias $[11,15,16,47,53]$. 
In order to eliminate SNPs and Indels from heterozygosity of Pst 11-281, we used the Illumina sequenced data of 11-281 to control SNP and Indel callings. Alignment of the Illumina data to the assembled reference genome followed above mentioned BWA-mem and GATK procedures. The variants from all 30 mutants were filtered by removing heterozygous sites of SNPs and Indels from both the primary scaffolds and haplotigs.

\section{Characterization of genomic variation in mutants}

The effect of SNPs and Indels concerning gene functions were determined separately using the program SnpEff version 4.3 t [76]. To begin with SnpEff, the Pst 11-281 genome database was built via inputting the assembled genome and GFF3 formatted file derived from MAKER2. Variants were annotated using the database we built under the default settings. The mutations were assigned to impact categories from the SnpEff analysis, including high, moderate, modifier and low variants. The associated amino acid variations and whether they are in accordance with deleterious mutations were also detected using SnpEff. Only the deleterious mutations with high and moderate impacts, e.g. start lost, stop gained and missense variant, frameshift variants, etc., were selected for the further identification. Mutations with modifiers and low effect impacts, which did not impact directly on the genetic variants, were excluded.

\section{Association analysis between mutations and avirulence/ virulence phenotypes}

Genes from isolate 11-281 with deleterious mutations were extracted from the annotated VCF formatted file from the SnpEff outputs. Association between mutated genes and avirulence/virulence phenotypes were analyzed using genome association and prediction integrated tool (GAPIT version 3.0) in the R program $[77,78]$. The recorded ITs in numeric and mutated genes converted to numeric formats were used as phenotypic and genotypic inputs for the GAPIT analysis. The mixed linear model (MLM), which incorporated fixed and random effects, was implemented in the association analysis. SNPs and Indels were considered significantly or highly associated with avirulence/virulence phenotypes if $P$ value $\leq 0.05$ or $P$ value $\leq 0.001$, respectively.

\section{Identification of Avr candidates}

The associated genes and their predicted proteins were obtained from the GAPIT analysis. SPs were predicted from the proteins following the previously described pipeline for determining rust secretomes [43]. Proteins with signal peptides, which are presumed to have extracellular functions, were identified using SignalP 5.0 [79]. Proteins with predicted sequences containing transmembrane helices were excluded from the set of predicted extracellular proteins using TMHMM version 2.0 [80]. Selected SPs associated with avirulence/virulence phenotypes, which also had the amino acid changes, were identified as $A v r$ candidates. In addition, genes obtained from high association with $P$ value $\leq 0.001$ regardless SPs were predicted to be another set of putative effectors.

\section{Characterization of Avr genes candidates}

To characterize $A v r$ effector candidates, multiple criteria that have been commonly used to identify effectors were used. These criteria include: 1) the size of amino acid sequence less than $300 ; 2)$ cysteine-rich with the percentage equal to or greater than $3 \%$; 3 ) predicted by the program EffectorP; 4) genus or species specific; 5) no

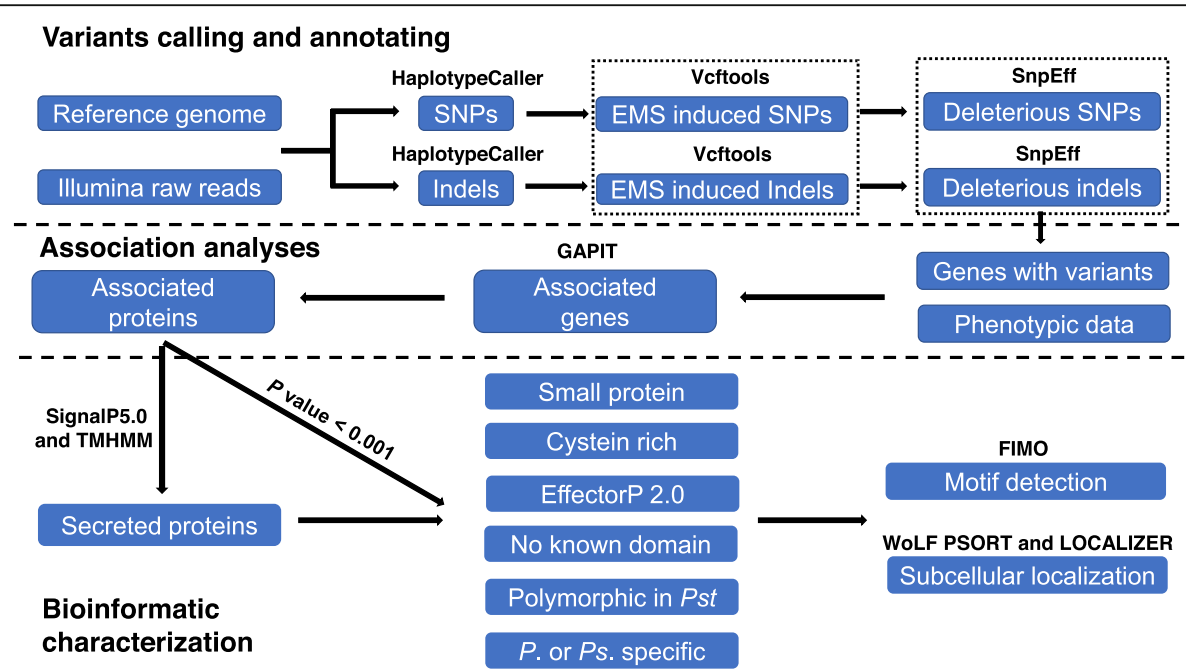

Fig. 9 A schematic procedure for variants calling and annotating, association analysis and effector evaluation. Variants calling and annotating were implemented mainly using GATK HaplotypeCaller and SnpEff, respectively. The output files were integrated with phenotypic data to fulfill association analyses using GAPIT. The Avr effector candidates obtained from selected associated proteins were further evaluated and characterized in different aspects 
conserved domains and 6) polymorphic among P. striiformis isolates.

The amino acid lengths and cysteine percentages of candidate Avr effectors were calculated using a modified Python script [43]. Fungal effector prediction in secretomes were implemented using EffectorP version 2.0, which utilizes different approaches to predict effectors based on a large set of reported effectors [67]. In order to identify homologous relationships between sequences to generate orthologous groups, thirteen protein sequences in ten species, including Pst, P. striiformis f. sp. hordei (Psh, the barley stripe rust pathogen), P. triticina (Pt, the wheat leaf rust pathogen), Pgt, Puccinia coronata f. sp. avenae (Pca, the oat crown rust pathogen), Blumeria graminis f. sp. hordei (Bgh, the barley powdery mildew pathogen), Botrytis cinerea (Bc), Fusarium oxysporum f. sp. cepae (Foc), Fusarium graminearum (Fg), Melampsora larici-populina (Mlp) and Verticillium dahliae $(V d)$, were used to estimate the phylogenetic relationships using OrthoFinder version 2.3.1 [81]. A phylogenetic tree was inferred based on the orthogroups of each isolate, and an orthologous group number was assigned to each of the proteins. According to the orthologous groups of the Avr effector candidates, the genusspecific and species-specific proteins were identified. Since known obligated biotrophic effectors rarely have known functional domains [45], absence of domains is considered as one property of effectors. In this study, we assigned functional domains to the effector candidates using HMMSCAN searches against the PFAM protein family database using HmmerWeb version 2.36.0 [82] and searching InterPro database (http://www.ebi.ac.uk/Inter ProScan/). To identify polymorphic candidate effectors, eighteen candidates were searched for homologs from four existing $P S$ protein database (104E137A-, 93-210, 93TX-2 and PST-78) using BLAST (basic local alignment search tool) version 2.7.1+ with the E-value 1e-50, which stands for the extremely high confidence that the database match is a result of homologous relationships. Only the candidates found in all the four protein databases with $100 \%$ identity, no mismatch and no gaps detected were considered as monomorphism among Pst and otherwise, candidates were deemed to be polymorphic.

\section{Searching motifs and subcellular localizations of effectors in Pst and in the host}

Associated secreted proteins were searched for common effector motifs, including RxLR [44], RxLR-like motif [R/ $\mathrm{K} / \mathrm{H}] \mathrm{x}[\mathrm{L} / \mathrm{M} / \mathrm{I} / \mathrm{F} / \mathrm{Y} / \mathrm{W}] \mathrm{x}$ [83] and $\mathrm{YxSL}[\mathrm{R} / \mathrm{K}]$ [84] detected in oomycetes, $[\mathrm{L} / \mathrm{I}] \mathrm{xAR}$ and $[\mathrm{R} / \mathrm{K}] \mathrm{CxxCx} 12 \mathrm{H}[85]$ in some effectors of the rice blast pathogen (M. oryzae), [R/ $\mathrm{K}] \mathrm{VY}[\mathrm{L} / \mathrm{I}] \mathrm{R}$ [86] in $B g h,[\mathrm{Y} / \mathrm{F} / \mathrm{W}] \mathrm{xC}$ [46] in the wheat powdery mildew and rust effector candidates and $\mathrm{G}[\mathrm{I} / \mathrm{F} /$ $\mathrm{Y}][\mathrm{A} / \mathrm{L} / \mathrm{S} / \mathrm{T}] \mathrm{R}$ [27] in some effectors of the flax rust pathogen (M. lini). Motifs were scanned using FIMO version 5.1.1 in the MEME suite with a match $P$ value less than 0.0001 [87]. The subcellular localizations were predicted by amino acid sequence searching of the Fungi databases using the WoLF PSORT program (https:// wolfpsort.hgc.jp/). The localizations of effectors in plant cells were predicted using the program LOCALIZER version 1.0.4, which determines effector targets as in chloroplasts, mitochondria or nuclei using the mature effector sequences [43]. The workflow of variant calling, association analysis, effector identification and evaluation were presented in the Fig. 9.

\section{Supplementary information}

Supplementary information accompanies this paper at https://doi.org/10. 1186/s12864-020-6677-y.

\begin{abstract}
Additional file 1: Table S1. Infection types of the progenitor isolate 11-281 and derived 30 mutants of Puccinia striiformis f. sp. tritici on 18 wheat $Y r$ single-gene differentials. Table S2. Reads, rates and qualities of 30 Puccinia striiformis f. sp. tritici mutants mapped to the reference genome. Table S3. The distribution and density of SNPs and Indels on each scaffold. Table S4. Statistics of Indels of each mutant isolate in terms of insertions, deletions, and different lengths. Table S5. Number of SNPs, Indels, insertions and deletions of each mutant isolate identified from the isolate 11-281 haplotigs. Table S6. Genes highly associated to avirulence with $P$-value $<0.001$.
\end{abstract}

Additional file 2: Figure S1. Phylogenetic trees of Puccinia striiformis $f$. sp. tritici mutant isolates based on the EMS-induced SNPS. Figure S2. Types and frequencies of SNP effects detected from the reference genome haplotigs. A: The number and percentage of all EMS-induced SNPs for each type of effects. B: The types and percentages of deleterious SNP effects. Figure S3. Types and frequencies of Indel effects detected from the reference genome haplotigs. A: The number and percentages of all EMS-induced Indels for each type of effects. B: The types and percentages of deleterious Indel effects. Figure S4. Phylogenetic tree of the progenitor isolate 11-281 of Puccinia striiformis f. sp. tritici (Pst) together with other 12 fungal isolates. The phylogenetic tree was developed from 13 protein sequences using a hill-climbing algorithm with the GTRGAMMA model. 13 fungi isolates are Verticillium dahlia 12,008, Fusarium oxysporum f. sp. cepae FoC_Fus2, Fusarium graminearum ITEM_124, Blumeria graminis f. sp. hordei RACE1, Botrytis cinerea B05.10, Melampsora larici-populina 98AG31, Puccinia striiformis f. sp. tritici 104E137A-, 93-210, 11-281, Puccinia striiformis f. sp. hordei 93TX-2, Puccinia coronata f. sp. avenae 12SD80, Puccinia graminis f. sp. tritici CRL75-36-700-3 and Puccinia triticina BBBD Race 1. The numbers indicate the distances between nodes. Figure S5. Characterization of Puccinia striiformis f. sp. tritici Avr effector candidates in the Upset plot. A: 48 effector candidates of secreted protein (SP) genes. B: 14 effector candidates from non-SP genes. Figure S6. Percentages (\%) of the subcellular localization sites of effector candidates of Puccinia striiformis $\mathrm{f}$. sp. tritici in the fungal cells. A: Genes identified from secreted protein (SP) genes. B: Genes identified from non-SP genes. C: All 62 genes associated to avirulence genes. Figure S7. Percentages (\%) of the subcellular localization sites of effector candidates of Puccinia striiformis f. sp. tritici inside the host. A: Genes identified from secreted protein (SP) genes. B: Genes identified from non-SP genes. C: All 62 genes associated to avirulence genes.

Additional file 3: Table SE1. 62 genes considered as candidates for avirulence genes and their genome positions and derived amino acids. Table SE2. Orthogroups of Puccinia striiformis $\mathrm{f}$. sp. tritici (Pst) avirulence gene candidates in isolate Pst 11-281 detected in other 12 fungal isolates. Table SE3. Search results of candidate genes identified in Puccinia striiformis f. sp. tritici (Pst) isolate Pst 11-281 against four $P$. striiformis protein databases using NCBI BLAST. 


\section{Abbreviations}

Avr: Avirulence gene; BLAST: Basic local alignment search tool;"

BWA: Burrows-wheeler alignment; CTAB: Cetyl trimethylammonium bromide; EMS: Ethyl methanesulfonate; ETI: Effector-triggered immunity;

GATK: Genome analysis toolkit; Indels: Insertion/deletion; IT: Infection type; MLM: Mixed linear model; NCBI: National center of biological information; P: Probability; PAMP: Pathogen-associated molecular pattern; Pgt: Puccinia graminis f. sp. tritici; Ps: Puccinia striiformis; Psh: Puccinia striiformis f. sp. hordei; Pst: Puccinia striiformis f. sp. tritici; Pt: Puccinia triticina; PTI: PAMP triggered immunity; R: Resistance; SNP: Single nucleotide polymorphism; SP: Secreted protein; Yr: Yellow (stripe rust) resistance

\section{Acknowledgements}

This study was conducted in the facilities of U.S. Department of Agriculture, Agricultural Research Service and Washington State University (WSU), Pullman, Washington. Department of Plant Pathology, College of Agricultural, Human, and Natural Resource Sciences, Agricultural Research Center, Project No. WNP00663, Washington State University, Pullman, WA 99164-6430, USA. Technical support from WSU Information Technology staff is highly appreciated. The China Scholarship Council scholarship to YL is highly appreciated. We also acknowledge the Kamiak high performance computing clusters in WSU for providing computing resources. The study was partially presented at the American Phytopathological Society Annual Meeting, 4-7 August, 2019, Cleveland, OH, USA and published as a conference abstract (Phytopathology (109(10):S2.12, 2019).

\section{Authors' contributions}

$Y L$ participated in developing and increasing urediniospores of the mutant isolates, DNA extraction, data analyses, draft and revising the manuscript. CX participated in analyzing and interpreting the data and drafting and revising the manuscript; MW participated in selecting isolate, producing spores, inoculating plants, virulence data analysis and extracting genomic DNA; CY participated in inoculating plants, DNA extraction and data analyses; XC conceived and coordinated the study, designed the experiments, provided materials and resources, interpreted data and wrote the manuscript. All authors read and approved the final manuscript.

\section{Funding}

This study was supported by the U.S. Department of Agriculture, Agricultural Research Service (Project No. 2090-22000-018-00D) and Washington Grain Commission (Projects 13C-3061-5682; 13C-3061-3144). The funding bodies played no role in the design of the study and collection, analysis, and interpretation of data and in writing the manuscript.

\section{Availability of data and materials}

The whole genome of the progenitor isolate (11-281) sequenced, assembled and annotated as previously reported [49], was used as a reference genome in this study. The assembled genome sequence of $P$. striiformis isolate 11281 is available on GenBank under the accession number SBIN00000000. The version described in this article is version SBIN01000000. The raw data of isolate 11-281 used for this experiment has been submitted to NCBI with SRA study SRR8446446. The raw data of the 30 mutant isolates have been deposited in the NCBI under BioProject accession PRJNA587768 (containing SRA accessions SRR10413520 to SRR10413549) with the title "Puccinia striiformis f. sp. tritici strain:PST-mutants | isolate:PST-mutants_M11 Raw sequence reads". All analyzed data are provided in the additional files of this publication.

\section{Ethics approval and consent to participate}

Not applicable.

\section{Consent for publication}

Not applicable.

\section{Competing interests}

The authors declare that they have no competing interests.
Received: 8 November 2019 Accepted: 13 March 2020

Published online: 20 March 2020

\section{References}

1. Chen XM, Kang ZS. Introduction: history of research, symptoms, taxonomy of the pathogen, host range, distribution, and impact of stripe rust. In: Chen XM, Kang ZS, editors. Stripe Rust. Dordrecht, Springer; 2017. p. 1-33.

2. Wellings CR. Global status of stripe rust: a review of historical and current threats. Euphytica. 2011;179(1):129-41.

3. Chen XM. Epidemiology and control of stripe rust [Puccinia striiformis $\mathrm{f}$. $\mathrm{sp}$. tritici] on wheat. Can J Plant Pathol. 2005;27(3):314-37.

4. Bayles R, Flath K, Hovmøller M, de Vallavieille-Pope C. Breakdown of the Yr17 resistance to yellow rust of wheat in northern Europe. Agronomie. 2000;20:805-11.

5. de Vallavieille-Pope C, Ali S, Leconte M, Enjalbert J, Delos M, Jacques R. Virulence dynamics and regional structuring of Puccinia striiformis f. sp. tritici in France between 1984 and 2009. Plant Dis. 2012;96:131-40.

6. Liu T, Wan A, Liu D, Chen X. Changes of races and virulence genes in Puccinia striiformis $\mathrm{f}$. sp. tritici, the wheat stripe rust pathogen, in the United States from 1968 to 2009. Plant Dis. 2017;101(8):1522-32.

7. Wellings CR. Pucinia striiformis in Australia: a review of the incursion, evolution, and adaptation of stripe rust in the period 1979-2006. Aus J Agric Res. 2007;58(6):567-75.

8. Lei Y, Wang M, Wan A, Xia C, See DR, Zhang M, Chen X. Virulence and molecular characterization of experimental isolates of the stripe rust pathogen (Puccinia striiformis) indicate somatic recombination. Phytopathology. 2017;107(3):329-44.

9. Yuan C, Wang M, Skinner DZ, See DR, Xia C, Guo X, Chen X. Inheritance of virulence, construction of a linkage map, and mapping dominant virulence genes in Puccinia striiformis f. sp. tritici through characterization of a sexual population with genotyping-by-sequencing. Phytopathology. 2018;108(1): 133-41.

10. Li Y, Wang M, See DR, Chen X. Ethyl-methanesulfonate mutagenesis generated diverse isolates of Puccinia striiformis f. sp. tritici, the wheat stripe rust pathogen. World J Microbiol Biotechnol. 2019:35(2):28.

11. Greene EA, Codomo CA, Taylor NE, Henikoff JG, Till BJ, Reynolds SH, Enns LC, Burtner C, Johnson JE, Odden AR, Comai L. Spectrum of chemically induced mutations from a large-scale reverse genetic screen in Arabidopsis. Genetics. 2003;164:731-40.

12. Till BJ, Reynolds SH, Greene EA, Codomo CA, Enns LC, Johnson JE, Burtner C, Odden AR, Young K, Taylor NE, Henikoff JG. Large-scale discovery of induced point mutations with high-throughput TILLING. Genome Res. 2003; 13(3):524-30.

13. Flibotte S, Edgley ML, Chaudhry I, Taylor J, Neil SE, Rogula A, Zapf R, Hirst M, Butterfield Y, Jones SJ, Marra MA, Barstead RJ, Moerman DG. Whole-genome profiling of mutagenesis in Caenorhabditis elegans. Genetics. 2010;185(2): 431-41.

14. Thompson $\mathrm{O}$, Edgley M, Strasbourger $\mathrm{P}$, Flibotte $\mathrm{S}$, Ewing $\mathrm{B}$, Adair $\mathrm{R}$, Au V, Chaudhry I, Fernando L, Hutter H, Kieffer A, Lau J, Lee N, Miller A, Raymant G, Shen B, Shendure J, Taylor J, Turner EH, Hillier LW, Moerman DG, Waterston $\mathrm{RH}$. The million mutation project: a new approach to genetics in Caenorhabditis elegans. Genome Res. 2013;23(10):1749-62.

15. Mohd-Yusoff NF, Ruperao P, Tomoyoshi NE, Edwards D, Gresshoff PM, Biswas B, Batley J. Scanning the effects of ethyl methanesulfonate on the whole genome of Lotus japonicus using second-generation sequencing analysis. G3 (Bethesda). 2015;5(4):559-67.

16. Henry IM, Nagalakshmi U, Lieberman MC, Ngo KJ, Krasileva KV, VasquezGross H, Akhunova A, Akhunov E, Dubcovsky J, Tai TH, Comai L. Efficient genome-wide detection and cataloging of EMS-induced mutations using exome capture and next-generation sequencing. Plant Cell. 2014;26(4): 1382-97.

17. Shiwa Y, Fukushima-Tanaka S, Kasahara K, Horiuchi T, Yoshikawa H. Wholegenome profiling of a novel mutagenesis technique using proofreadingdeficient DNA polymerase delta. Int J Evol Biol. 2012;2012:860797.

18. Anderson C, Khan MA, Catanzariti AM, Jack CA, Nemri A, Lawrence GJ, Upadhyaya NM, Hardham AR, Ellis JG, Dodds PN, Jones DA. Genome analysis and avirulence gene cloning using a high-density RADseq linkage map of the flax rust fungus. Melampsora lini BMC Genomics. 2016;17:667.

19. Olsen O, Wang X, von Wettstein D. Sodium azide mutagenesis: preferential generation of AT--> GC transitions in the barley Ant18 gene. Proc Natl Acad Sci U S A. 1993;17:8043-7. 
20. Salcedo A, Rutter W, Wang S, Akhunova A, Bolus S, Chao S, Anderson N, De Soto MF, Rouse M, Szabo L, Bowden RL. Variation in the AvrSr35 gene determines Sr35 resistance against wheat stem rust race Ug99. Science. 2017;358(6370):1604-6.

21. Steuernagel B, Periyannan SK, Hernandez-Pinzon I, Witek K, Rouse MN, Yu G, Hatta A, Ayliffe M, Bariana H, Jones JD, Lagudah ES, Wulff BB. Rapid cloning of disease-resistance genes in plants using mutagenesis and sequence capture. Nat Biotechnol. 2016;34(6):652-5.

22. Flor HH. Current status of the gene-for-gene concept. Annu Rev Phytopathol. 1971;9:275-96.

23. Jones JD, Dangl JL. The plant immune system. Nature. 2006;444(7117):323-9.

24. de Wit PJ. Cladosporium fulvum effectors: weapons in the arms race with tomato. Annu Rev Phytopathol. 2016;54:1-23.

25. Chen J, Upadhyaya NM, Ortiz D, Sperschneider J, Li F, Bouton C, Breen S, Dong C, Xu B, Zhang X, Mago R, Newell K, Xia X, Bernoux M, Taylor JM, Steffenson B, Jin Y, Zhang P, Kanyuka K, Figueroa M, Ellis JG, Park RF, Dodds PN. Loss of AvrSr50 by somatic exchange in stem rust leads to virulence for Sr50 resistance in wheat. Science. 2017;358(6370):1607-10.

26. Upadhyaya NM, Mago R, Staskawicz BJ, Ayliffe MA, Ellis JG, Dodds PN. A bacterial type III secretion assay for delivery of fungal effector proteins into wheat. Mol Plant-Microbe Interact. 2014;27(3):255-64

27. Catanzariti AM, Dodds PN, Lawrence GJ, Ayliffe MA, Ellis JG. Haustorially expressed secreted proteins from flax rust are highly enriched for avirulence elicitors. Plant Cell. 2006;18(1):243-56.

28. Dodds PN, Lawrence GJ, Catanzariti AM, Ayliffe MA, Ellis JG. The Melampsora lini AvrL567 avirulence genes are expressed in haustoria and their products are recognized inside plant cells. Plant Cell. 2004;16(3):755-68.

29. Dagvadorj B, Ozketen AC, Andac A, Duggan C, Bozkurt TO, Akkaya MS. A Puccinia striiformis f. sp. tritici secreted protein activates plant immunity at the cell surface. Sci Rep. 2017;7(1):1141.

30. Zhao M, Wang J, Ji S, Chen Z, Xu J, Tang C, Chen S, Kang Z, Wang X. Candidate effector Pst_8713 impairs the plant immunity and contributes to virulence of Puccinia striiformis f. sp. tritici. Front. Plant Sci. 2018;9:1294.

31. Yang Q, Huai B, Lu Y, Cai K, Guo J, Zhu X, Kang Z, Guo J. A stripe rust effector Pst18363 targets and stabilizes TaNUDX23 that promotes stripe rust disease. New Phytol. 2019. https://doi.org/10.1111/nph.16199.

32. Cantu D, Govindarajulu M, Kozik A, Wang M, Chen X, Kojima KK, Jurka J, Michelmore RW, Dubcovsky J. Next generation sequencing provides rapid access to the genome of Puccinia striiformis $\mathrm{f}$. sp. tritici, the causal agent of wheat stripe rust. PLoS One. 2011;6(8):e24230.

33. Cantu D, Segovia V, MacLean D, Bayles R, Chen X, Kamoun S, Dubcovsky J, Saunders DGO, Uauy C. Genome analyses of the wheat yellow (stripe) rust pathogen Puccinia striiformis f. sp. tritici reveal polymorphic and haustorial expressed secreted proteins as candidate effectors. BMC Genomics. 2013;14:270

34. Cuomo CA, Bakkeren G, Khalil HB, Panwar V, Joly D, Linning R, Sakthikumar S, Song X, Adiconis X, Fan L, Goldberg JM, Levin JZ, Young S, Zeng Q, Anikster Y, Bruce M, Wang M, Yin C, McCallum B, Szabo LJ, Hulbert S, Chen $X$, Fellers JP. Comparative analysis highlights variable genome content of wheat rusts and divergence of the mating Loci. G3 (Bethesda). 2017;7(2): 361-76

35. Kiran K, Rawal HC, Dubey H, Jaswal R, Bhardwaj SC, Prasad P, Pal D, Devanna BN, Sharma TR. Dissection of genomic features and variations of three pathotypes of Puccinia striiformis through whole genome sequencing. Sci Rep. 2017;7:42419.

36. Xia C, Wang M, Yin C, Cornejo OE, Hulbert SH, Chen X. Genome sequence resources for the wheat stripe rust pathogen (Puccinia striiformis f. sp. tritici) and the barley stripe rust pathogen (Puccinia striiformis f. sp. hordei). Mol Plant-Microbe Interact. 2018;31(11):1117-20.

37. Zheng W, Huang L, Huang J, Wang X, Chen X, Zhao J, Guo J, Zhuang H, Qiu C, Liu J, Liu H, Huang X, Pei G, Zhan G, Tang C, Cheng Y, Liu M, Zhang J, Zhao Z, Zhang S, Han Q, Han D, Zhang H, Zhao J, Gao X, Wang J, Ni P, Dong W, Yang L, Yang H, Xu JR, Zhang G, Kang Z. High genome heterozygosity and endemic genetic recombination in the wheat stripe rust fungus. Nat Commun. 2013;4:2673.

38. Schwessinger B, Sperschneider J, Cuddy WS, Garnica DP, Miller ME, Taylor JM, Dodds PN, Figueroa M, Park RF, Rathjen JP. A near-complete haplotypephased genome of the dikaryotic wheat stripe rust fungus Puccinia striiformis $f$ sp tritici reveals high interhaplotype diversity. MBio. 2018;9:e02275-17.

39. Xia C, Wang M, Cornejo OE, Jiwan DA, See DR, Chen X. Secretome characterization and correlation analysis reveal putative pathogenicity mechanisms and identify candidate avirulence genes in the wheat stripe rust fungus Puccinia striiformis f sp tritici. Front Microbiol. 2017;8:2394.

40. Wu JQ, Sakthikumar S, Dong C, Zhang P, Cuomo CA, Park RF. Comparative genomics integrated with association analysis identifies candidate effector genes corresponding to Lr20 in phenotype-paired Puccinia triticina isolates from Australia. Front Plant Sci. 2017;8:148.

41. Saunders DG, Win J, Cano LM, Szabo LJ, Kamoun S, Raffaele S. Using hierarchical clustering of secreted protein families to classify and rank candidate effectors of rust fungi. PLoS One. 2012;7(1):e29847.

42. Sperschneider J, Dodds PN, Gardiner DM, Manners JM, Singh KB, Taylor JM. Advances and challenges in computational prediction of effectors from plant pathogenic fungi. PLoS Pathog. 2015;11(5):e1004806.

43. Sperschneider J, Dodds PN, Taylor JM, Duplessis S. Computational methods for predicting effectors in rust pathogens. Methods Mol Biol. 1659;2017:73-83.

44. Whisson SC, Boevink PC, Moleleki L, Avrova AO, Morales JG, Gilroy EM, Armstrong MR, Grouffaud S, van West P, Chapman S, Hein I, Toth IK, Pritchard L, Birch PR. A translocation signal for delivery of oomycete effector proteins into host plant cells. Nature. 2007;450(7166):115-8.

45. Lo Presti L, Lanver D, Schweizer G, Tanaka S, Liang L, Tollot M, Zuccaro A, Reissmann S, Kahmann R. Fungal effectors and plant susceptibility. Annu Rev Plant Biol. 2015;66:513-45.

46. Godfrey D, Böhlenius H, Pedersen C, Zhang Z, Emmersen J, ThordalChristensen $\mathrm{H}$. Powdery mildew fungal effector candidates share $\mathrm{N}$-terminal Y/F/WXC-motif. BMC Genomics. 2010;11(1):317.

47. Duplessis S, Cuomo CA, Lin YC, Aerts A, Tisserant E, Veneault-Fourrey C, Joly DL, Hacquard S, Amselem J, Cantarel BL, Chiu R, Coutinho PM, Feau N, Field M, Frey P, Gelhaye E, Goldberg J, Grabherr MG, Kodira CD, Kohler A, Kues U, Lindquist EA, Lucas SM, Mago R, Mauceli E, Morin E, Murat C, Pangilinan JL, Park R, Pearson M, Quesneville H, Rouhier N, Sakthikumar S, Salamov AA, Schmutz J, Selles B, Shapiro H, Tanguay P, Tuskan GA, Henrissat B, Van de Peer Y, Rouze P, Ellis JG, Dodds PN, Schein JE, Zhong S, Hamelin RC, Grigoriev IV, Szabo L, Martin F. Obligate biotrophy features unraveled by the genomic analysis of rust fungi. Proc Natl Acad Sci U S A. 2011;108(22): 9166-71.

48. Wan A, Chen X. Virulence characterization of Puccinia striiformis f. sp. tritici using a new set of $Y r$ single-gene line differentials in the United States in 2010. Plant Dis. 2014;98(11):1534-42.

49. Li Y, Xia C, Wang M, Yin C, Chen X. Genome sequence resource of a Puccinia striiformis isolate infecting wheatgrass. Phytopathology. 2019;109(9): 1509-12.

50. McDonald BA, Linde C. Pathogen population genetics, evolutionary potential, and durable resistance. Annu Rev Phytopathol. 2002;40:349-79.

51. Anderson P. Mutagenesis. In: Epstein HF, Shakes DC, editors. C. elegans: modern biological analysis of an organism. New York: Academic Press; 1995. p. 31-58.

52. Bentley A, MacLennan B, Calvo J, Dearolf CR. Targeted recovery of mutations in Drosophila. Genetics. 2000:156(3):1169-73.

53. Shirasawa K, Hirakawa H, Nunome T, Tabata S, Isobe S. Genome-wide survey of artificial mutations induced by ethyl methanesulfonate and gamma rays in tomato. Plant Biotechnol J. 2016;14(1):51-60.

54. Uchida N, Sakamoto T, Kurata T, Tasaka M. Identification of EMS-induced causal mutations in a non-reference Arabidopsis thaliana accession by whole genome sequencing. Plant Cell Physiol. 2011;52(4):716-22.

55. Rigola D, van Oeveren J, Janssen A, Bonne A, Schneiders $H$, van der Poel HJ, van Orsouw NJ, Hogers RC, de Both MT, van Eijk MJ. High-throughput detection of induced mutations and natural variation using KeyPoint technology. PLoS One. 2009;4(3):e4761.

56. Chin CS, Peluso P, Sedlazeck FJ, Nattestad M, Concepcion GT, Clum A, Dunn C, O'Malley R, Figueroa-Balderas R, Morales-Cruz A, Cramer GR. Phased diploid genome assembly with single-molecule real-time sequencing. Nat Methods. 2016;13(12):1050.

57. Slade AJ, Fuerstenberg SI, Loeffler D, Steine MN, Facciotti D. A reverse genetic, nontransgenic approach to wheat crop improvement by TILLING. Nat Biotechnol. 2005;23(1):75-81.

58. Cheng P, Chen XM, See DR. Grass hosts harbor more diverse isolates of Puccinia striiformis than cereal crops. Phytopathology. 2016;106(4):362-71.

59. Cheng P, Chen XM. Virulence and molecular analyses support asexual reproduction of Puccinia striiformis $\mathrm{f}$. sp. tritici in the U.S. Pacific northwest. Phytopathology. 2014;104(11):1208-20.

60. Xia C, Wan A, Wang M, Jiwan DA, See DR, Chen X. Secreted protein gene derived-single nucleotide polymorphisms (SP-SNPS) reveal population 
diversity and differentiation of Puccinia striiformis f. sp. tritici in the United States. Fungal Biol. 2016;120(5):729-44.

61. Wan A, Chen X, Yuen J. Races of Puccinia striiformis f. sp. tritici in the United States in 2011 and 2012 and comparison with races in 2010. Plant Dis. 2016; 100(5):966-75.

62. Guyon K, Balagué C, Roby D, Raffaele S. Secretome analysis reveals effector candidates associated with broad host range necrotrophy in the fungal plant pathogen Sclerotinia sclerotiorum. BMC Genomics. 2014;15(1):336.

63. Sperschneider J, Gardiner DM, Taylor JM, Hane JK, Singh KB, Manners JM. A comparative hidden Markov model analysis pipeline identifies proteins characteristic of cereal-infecting fungi. BMC Genomics. 2013;14(1):807.

64. Syme RA, Hane JK, Friesen TL, Oliver RP. Resequencing and comparative genomics of Stagonospora nodorum: sectional gene absence and effector discovery. G3 (Bethesda). 2013;3(6):959-69.

65. Sedzielewska Toro K, Brachmann A. The effector candidate repertoire of the arbuscular mycorrhizal fungus Rhizophagus clarus. BMC Genomics. 2016;17:101.

66. Bohnert HU, Fudal I, Dioh W, Tharreau D, Notteghem JL, Lebrun MH. A putative polyketide synthase/peptide synthetase from Magnaporthe grisea signals pathogen attack to resistant rice. Plant Cell. 2004;16(9):2499-513.

67. Sperschneider J, Dodds PN, Gardiner DM, Singh KB, Taylor JM. Improved prediction of fungal effector proteins from secretomes with EffectorP 2.0. Mol Plant Pathol. 2018;19(9):2094-110.

68. Parlange F, Daverdin G, Fudal I, Kuhn ML, Balesdent MH, Blaise F, GrezesBesset B, Rouxel T. Leptosphaeria maculans avirulence gene AvrLm4-7 confers a dual recognition specificity by the $R / m 4$ and $R / m 7$ resistance genes of oilseed rape, and circumvents R/m4-mediated recognition through a single amino acid change. Mol Microbiol. 2009;71(4):851-63.

69. Ve T, Williams SJ, Catanzariti AM, Rafiqi M, Rahman M, Ellis JG, Hardham AR, Jones DA, Anderson PA, Dodds PN, Kobe B. Structures of the flax-rust effector AvrM reveal insights into the molecular basis of plant-cell entry and effector-triggered immunity. Proc Natl Acad Sci U S A. 2013;110(43):17594-9.

70. Uhse S, Djamei A. Effectors of plant-colonizing fungi and beyond. PLoS Pathog. 2018;14(6):e1006992.

71. Sperschneider J, Catanzariti AM, DeBoer K, Petre B, Gardiner DM, Singh KB, Dodds PN, Taylor JM. LOCALIZER: subcellular localization prediction of both plant and effector proteins in the plant cell. Sci Rep. 2017;7:44598.

72. Yin C, Ramachandran SR, Zhai Y, Bu C, Pappu HR, Hulbert SH. A novel fungal effector from Puccinia graminis suppressing RNA silencing and plant defense responses. New Phytol. 2019;222(3):1561-72.

73. Chen XM, Line RF, Leung $H$. Relationship between virulence variation and DNA polymorphism in Puccinia striiformis. Phytopathology. 1993;83:1489-97.

74. Bolger AM, Lohse M, Usadel B. Trimmomatic: a flexible trimmer for Illumina sequence data. Bioinformatics. 2014;30(15):2114-20.

75. Li H, Durbin R. Fast and accurate short read alignment with burrowswheeler transform. Bioinformatics. 2009;25(14):1754-60.

76. Cingolani P, Platts A, Wang Le L, Coon M, Nguyen T, Wang L, Land SJ, Lu X, Ruden DM. A program for annotating and predicting the effects of single nucleotide polymorphisms, SnpEff: SNPs in the genome of Drosophila melanogaster strain W1118; iso-2; iso-3. Fly (Austin). 2012;6(2):80-92.

77. Bradbury PJ, Zhang Z, Kroon DE, Casstevens TM, Ramdoss Y, Buckler ES. TASSEL: software for association mapping of complex traits in diverse samples. Bioinformatics. 2007;23(19):2633-5.

78. Lipka AE, Tian F, Wang Q, Peiffer J, Li M, Bradbury PJ, Gore MA, Buckler ES, Zhang Z. GAPIT: genome association and prediction integrated tool. Bioinformatics. 2012;28(18):2397-9.

79. Almagro Armenteros JJ, Tsirigos KD, Sonderby CK, Petersen TN, Winther O, Brunak S, von Heijne G, Nielsen H. SignalP 5.0 improves signal peptide predictions using deep neural networks. Nat Biotechnol. 2019;37(4):420-3.

80. Krogh A, Larsson B, von Heijne G, Sonnhammer EL. Predicting transmembrane protein topology with a hidden Markov model: application to complete genomes. J Mol Biol. 2001;305(3):567-80.

81. Emms DM, Kelly S. OrthoFinder: solving fundamental biases in whole genome comparisons dramatically improves orthogroup inference accuracy. Genome Biol. 2015;16:157.

82. Potter SC, Luciani A, Eddy SR, Park Y, Lopez R, Finn RD. HMMER web server: 2018 update. Nucleic Acids Res. 2018;46(W1):W200-W04.

83. Kale SD, Gu B, Capelluto DG, Dou D, Feldman E, Rumore A, Arredondo FD, Hanlon R, Fudal I, Rouxel T, Lawrence CB, Shan W, Tyler BM. External lipid $\mathrm{PI} 3 \mathrm{P}$ mediates entry of eukaryotic pathogen effectors into plant and animal host cells. Cell. 2010;142(2):284-95.
84. Lévesque CA, Brouwer H, Cano L, Hamilton JP, Holt C, Huitema E, Raffaele S, Robideau GP, Thines M, Win J, Zerillo MM. Genome sequence of the necrotrophic plant pathogen Pythium ultimum reveals original pathogenicity mechanisms and effector repertoire. Genome Biol. 2010;11(7):R73.

85. Yoshida K, Saitoh H, Fujisawa S, Kanzaki H, Matsumura H, Yoshida K, Tosa Y, Chuma I, Takano Y, Win J, Kamoun S, Terauchi R. Association genetics reveals three novel avirulence genes from the rice blast fungal pathogen Magnaporthe oryzae. Plant Cell. 2009;21(5):1573-91.

86. Ridout CJ, Skamnioti P, Porritt O, Sacristan S, Jones JD, Brown JK. Multiple avirulence paralogues in cereal powdery mildew fungi may contribute to parasite fitness and defeat of plant resistance. Plant Cell. 2006;18(9):2402-14.

87. Grant CE, Bailey TL, Noble WS. FIMO: scanning for occurrences of a given motif. Bioinformatics. 2011;27(7):1017-8

\section{Publisher's Note}

Springer Nature remains neutral with regard to jurisdictional claims in published maps and institutional affiliations.
Ready to submit your research? Choose BMC and benefit from:

- fast, convenient online submission

- thorough peer review by experienced researchers in your field

- rapid publication on acceptance

- support for research data, including large and complex data types

- gold Open Access which fosters wider collaboration and increased citations

- maximum visibility for your research: over $100 \mathrm{M}$ website views per year

At BMC, research is always in progress.

Learn more biomedcentral.com/submissions 